\title{
THE SCIENCE OF REVERSE OSMOSIS - MECHANISMS, MEMBRANES, TRANSPORT AND APPLICATIONS
}

\author{
S. Sourirajan \\ Division of Chemistry, National Research Council of Canada, \\ Ottawa, Canada KlA OR9
}

\begin{abstract}
A view of the science of reverse osmosis on the basis of the preferential sorption-capillary flow mechanism is presented. Preferential sorption at the membrane-solution interface is a function of solute-solventmembrane material interactions arising from polar-, steric-, nonpolar-, and/or ionic-character of each one of the above components. Quantitative parameters for characterizing solutes and membrane materials at aqueous solution-membrane interfaces have been generated. Basic transport equations suitable for membrane specification and system analysis, and applicable for all membrane materials and membranes at all levels of solute separations have been developed for reverse osmosis systems involving aqueous solutions and preferential sorption of water at the membrane-solution interface. The polar, steric, and nonpolar parameters characterizing solutes have been built into the above transport equations through appropriate additional equations and correlations. As a result, it is now possible to predict the performance of a membrane for a large number of single and mixed solute aqueous feed solutions from only a single set of experimental reverse osmosis data for a reference $\mathrm{NaCl}-\mathrm{H}_{2} \mathrm{O}$ feed solution. This is illustrated.
\end{abstract}

\section{INTRODUCTION}

Reverse osmosis is a general process for the separation of substances in fluid (liquid or gaseous) solution by permeation under pressure through an appropriate membrane (Ref. 1,2). The physicochemical basis for reverse osmosis separations, the materials science of reverse osmosis membranes, and the engineering science of reverse osmosis transport together constitute the science of reverse osmosis; all applications of reverse osmosis arise from this science. To present this point of view is the purpose of this paper.

\section{MECHAN ISMS}

Several mechanisms for reverse osmosis have been suggested (Ref. 3-16), and obviously each one


Fig. 1. Schematic representation of preferential sorption-capillary flow mechanism for reverse osmosis separation of sodium chloride in aqueous solution using an appropriate porous membrane.

has its own justification. The origin of the current worldwide interest and activity in the field of reverse osmosis is the original development of the now well-known asymmetric porous cellulose acetate membranes (Ref. 17-19) which have proved useful for many water treatment and other applications. This development itself was the result of a particular approach to 
the subject, described as the "preferential sorption-capillary flow mechanism" (Ref. 1,2,20,21) for reverse osmosis. This mechanism is consistent with all known experimental facts on reverse osmosis separations; it immediately directs attention to the existence of the science of reverse osmosis; and it offers a rational basis for the useful development of the science of reverse osmosis in all its aspects. For these reasons, the preferential sorption-capillary flow mechanism for reverse osmosis is the basis of this paper.

\section{The preferential sorption-capillary flow mechanism}

According to this mechanism, reverse osmosis separation is the combined result of preferential sorption of one of the constituents of the fluid mixture at the membrane-solution interface and fluid permeation through the microporous membrane. An appropriate chemical nature of the membrane surface in contact with the solution and the existence of pores of appropriate size and number on the area of the membrane at the interface together constitute the indispensable twin-requirement for the practical success of this separation process. In the context of this mechanism, the term "preferential sorption" refers to the existence of a steep concentration gradient at the membrane-solution interface, and the terms "pore" and "capillary" refer to any void space (whatever be its origin or size) connecting the high pressure and low pressure sides of the membrane, through which fluid permeation and material transport can occur during reverse osmosis. Figure $l$ is a schematic representation of the above mechanism for the separation of sodium chloride in aqueous solution in a reverse osmosis system where water is preferentially sorbed (i.e, solute is negatively adsorbed) at the membrane solution interface.

\section{Consequences of the above mechanism}

For reverse osmosis separation to take place, one of the constituents of the feed solution must be preferentially sorbed at the membrane-solution interface. Thus the physicochemical criteria governing preferential sorption at fluid-solid interfaces constitute a fundamental aspect of this mechanism. The surface layer of a successful reverse osmosis membrane is microporous and heterogeneous at all levels of solute separation. To reduce resistance to fluid flow during reverse osmosis, the surface layer of the membrane must be as thin as possible, and the overall porous structure of the membrane must be asymmetric. Reverse osmosis is not limited to any particular level of solute separation; the process encompasses all possible levels of solute separation. With an appropriate material for the membrane surface, practically any degree of solute separation is possible by simply changing the average pore size on the membrane surface, and the operating conditions of the reverse osmosis experiment. There is a critical pore diameter for maximum solute separation and fluid permeability for each system. The magnitude of this critical pore diameter is a function of the strength and magnitude of preferential sorption at the membrane-solution interface. Thus reverse osmosis is not size-separation by sieve-filtration. With respect to a given membrane material-solution system, solute and solvent flux through the membrane depend on the size, number, and distribution of pores on the membrane surface, and the thickness of the surface layer of the membrane; thus solute separation and membrane flux are two independent variables in the process of developing reverse osmosis membranes. The feed solution for reverse osmosis can be aqueous or nonaqueous, and in the liquid or the gaseous phase; hence the reverse osmosis technique is applicable for the separation of substances in aqueous solutions, nonaqueous solutions or gaseous mixtures. The solute in the feed solution for reverse osmosis can be organic or inorganic, and ionic or nonionic. Either solvent or solute (or neither) can be preferentially sorbed at the membrane-solution interface depending on the chemical nature of the solution and that of the material of the membrane surface. A given membrane can give different levels of separation for different solutes due to differences in preferential sorption at the membrane-solution interface, and mobility of the preferentially sorbed species through the membrane pores; this possibility can lead to fractionation of solutes by reverse osmosis from feed solutions involving mixed solutes, and also the existence of specific equisorptic compositions for binary mixtures and the shift in such compositions under different reverse osmosis experimental conditions.

The foregoing consequences of the preferential sorption-capillary flow mechanism have far reaching scientific and technological significance. In the light of the above mechanism, reverse osmosis reveals itself as a new science, the development of which can lead to practical applications of enormous benefit to all mankind.

\section{Solute-solvent-membrane material interactions}

Preferential sorption at the membrane-solution interface is a function of solute-solventmembrane material interactions. These interactions arise in general from polar (hydrogen bonding), steric, nonpolar, and/or ionic character of each one of the above components. The overall result of these interactions determines whether solvent or solute, or neither, is preferentially sorbed at the membrane-solution interface.

The following discussion is limited by space requirements. Unless otherwise stated, all data in this paper refer to aqueous solutions, single-solute systems, and polymeric membranes made 
of cellulose acetate (acetyl content, 39.8\%) material, and reverse osmosis operation at $25^{\circ} \mathrm{C}$, where fraction solute separation : is defined as:

$$
f=\frac{\text { solute molality in feed }\left(m_{1}\right)-\text { solute molality in product }\left(m_{3}\right)}{\text { solute molality in feed }\left(m_{l}\right)}
$$

and the terms "product" and "product rate" refer to the membrane permeated solution corresponding to a given membrane area and practically zero product water recovery.

Considering reverse osmosis systems with cellulose acetate membranes and aqueous feed solutions involving organic or inorganic solutes, the solvent (water) is polar, the solute may have polar, steric, nonpolar, and/or ionic character, and the polymer (membrane material) has both polar and nonpolar character. Now three cases arise: (a) when the polymer attracts water more than the solute (or repels solute more than water), water is preferentially sorbed at the membrane-solution interface resulting in positive solute separation in reverse osmosis; (b) when the polymer attracts water to the same extent as the solute, neither water nor solute is preferentially sorbed at the membrane-solution interface, in which case no solute separation is possible in reverse osmosis whatever be the porous structure of the membrane; and (c) when the polymer attracts the solute more than water, the solute is preferentially sorbed at the membrane-solution interface, in which case solute separation in reverse osmosis can be positive, negative, or zero depending on the relative mobility of the solute molecule, compared to water, under the experimental conditions. Using appropriate parameters to represent the polar, steric, nonpolar, and/or ionic character of the solute molecule, all the above three cases have been illustrated in the literature (Ref. 22-30).

\section{Polar parameters for characterizing solutes}

The polar character of a solute molecule can be expressed in quantitative terms by either one of the following parameters: ( $i)$ the hydrogen bonding ability of the solute as represented by its $\Delta \nu_{S}$ (acidity) (relative shift in the $\mathrm{OH}$ band maximum in the IR spectra of the solute in $\mathrm{CC}_{4} 4$ and ether solutions) or $\Delta \nu_{\mathrm{s}}$ (basicity) (relative shift in the OD band maximum in the IR spectra of $\mathrm{CH}_{3} \mathrm{OD}$ in benzene and the proton accepting solvent used as solute in reverse osmosis), or ( $i i)$ the $\mathrm{pK}_{a}\left(=-\log \mathrm{K}_{\mathrm{a}}\right.$ (dissociation constant)) of solute, or ( $\left.i i_{i}\right)$ the Taft $(\sigma *$ or $\Sigma \sigma *)$ or Hammett $(\sigma$ or $\Sigma \sigma)$ number for the substituent group in the solute molecule with reference to a given functional group, or (iv) the interfacial free energy parameter (- $\Delta \Delta G / R T)$ for the nonionized solute molecule and/or the dissociated ion in solution. The significance of each one of the above parameters has been discussed in the literature (Ref. 22).

Unique correlations exist between data on reverse osmosis separations and those of each one of the above parameters. While the free energy parameter $(-\Delta \Delta G / R T)$ is a property of the solute at the membrane-solution interface, the other three polar parameters represent the property of the solute in the bulk solution phase. Since reverse osmosis separation is governed by the property of the solute at the interface, the existence of unique correlations between data on reverse osmosis separations and those on $\Delta \nu_{s}$ (acidity) or $\Delta v_{s}$ (basicity), $\mathrm{pK}_{\mathrm{a}}$ and $\sum \sigma^{*}$ or $\Sigma \sigma$ shows that the property of the solute in the bulk solution phase and the corresponding property of the solute in the membrane-solution interface are uniquely related.

Criteria for preferential sorption. Experimental reverse osmosis data show (Ref. 23-26) that cellulose acetate molecule behaves as a net proton acceptor (base). Therefore a solute which is a proton donor (such as alcohols, phenols and acids) is attracted towards the membrane surface, and a solute which is a proton acceptor (such as aldehydes, ketones, ethers, esters and tertiary amines) is repelled away from the membrane surface. Consequently, lower acidity for solute (i.e., lower $\Delta \nu_{s}$ (acidity), or higher $\Delta \nu_{s}$ (basicity), higher $p K_{a}$ or lower $\sum \sigma^{*}$ or $\Sigma \sigma)$ increases preferential sorption of water at the membrane-solution interface. The acidity of water is quantitatively expressed by the values of $\Delta \nu_{s}$ (acidity) $=250 \mathrm{~cm}^{-1}$ and

$\Sigma \sigma^{*}=0.49$. When the acidity of the solute is less than that of water, the latter is preferentially sorbed at the membrane-solution interface; and, when the acidity of the solute is more than that of water, solute is preferentially sorbed at the interface. Further, since ions are repelled in the vicinity of membrane materials of low dielectric constant (Ref. 4,7), water is preferentially sorbed at the membrane-solution interface for feed solutions involving ionized solutes. Experiments with partially dissociated mono-carboxylic acid-solutes show (Ref. 23,27) that preferential sorption of water, and hence solute separation in reverse osmosis increase with increase in the degree of dissociation; further, for the cellulose acetate membranes, the change in preferential sorption at interface from water to nonionized acid occurs at a $\mathrm{pK}_{\mathrm{a}}$ value of 4.2 , above which water is preferentially sorbed, and at which neither is preferentially sorbed. The $\mathrm{pk}_{a}$ value of 4.2 corresponds to benzoic acid. On either side of $\mathrm{pK}_{\mathrm{a}}=4.2$, there is a region of $\mathrm{pK}_{\mathrm{a}}$ values $(3.9$ to 4.7$)$ in which very little preferential sorption occurs. Numerical values of the polar parameter $\Delta \nu_{s}$ (acidity), $\Delta v_{s}$ (basicity), $\mathrm{pK}_{\mathrm{a}}$ and $\Sigma \sigma$ or $\Sigma \sigma *$ are available in the literature for many organic solutes (Ref. 22).

The polar interfacial free energy parameter $(-\Delta \Delta G / R T)$. This is an operational parameter for predicting reverse osmosis separations from minimum of experimental data (see later discussion). 
This parameter does not offer any criterion for preferential sorption at the membrane-solution interface; on the other hand, when water is preferentially sorbed at the membrane solution interface, $-\triangle \Delta G / R T$ gives a quantitative measure of solute repulsion at the interface on a relative scale. This parameter was initially developed for inorganic ions, and later extended to nonionized organic solutes, organic ions and inorganic ion-pairs (Ref. $30-34)$. The scientific basis for this parameter arises from (i) Born equation for ion-solvent interaction (free energy of hydration) as applied to the bulk solution phase and the membrane-solution interface (Ref. 30,35), ( $i$ i) the thermodynamic basis of Hammett and Taft equations representing the effect of structure on reaction rates and equilibria (Ref. 36), ( $i \mathrm{i}$ ) the relationship between the parameters of Taft equation $\left(\rho * \sum \sigma *\right)$ (Ref. 36) and data on solute transport parameter $D_{A M} / K \delta$ (see discussion on transport) for different solutes (Ref. 37-39) and

(iv) the functional similarity of the thermodynamic quantity $\Delta \Delta F^{\ddagger}$ representing the transition state free energy change (Ref. 36) and the quantity $\Delta \Delta G$ defined as

$\Delta \Delta G=\Delta G_{1}-\Delta G_{B}$

where $\Delta G$ represents the free energy of hydration for the solute species, and the subscripts $I$ and $B$ represent the membrane-solution interface and the bulk solution phase respectively. The quantity $-\triangle \Delta G / R T$ is a function of the chemical nature of the solute, solvent and membrane material, and it is independent of the porous structure of the membrane used. A lower value of $-\triangle \Delta G / R T$ for the solute yields a lower value for $D_{A M} / K \delta$ for the solute and hence higher solute separation in reverse osmosis.

The values of $\Delta \Delta G$, and hence $-\triangle \Delta G / R T$, for different ions and nonionized solute molecules can be calculated from data on $\Delta G_{B}$ (Ref. 40,41 ) and reverse osmosis experimental data on $D_{A M} / K \delta$ for different solutes (Ref. 30, 31). Table l gives data on $-\triangle \Delta G / R T$ for several inorganic and organic ions, and inorganic ion-pairs for cellulose acetate membrane-aqueous solution interfaces. For nonionized polar organic solutes, it has been found that the values of $\Delta G_{B}$ and $\Delta G_{1}$ are simply additive functions of the structural groups in the molecule, so that they can be expressed as

$\Delta G_{B}=\sum \gamma_{B}$ (structural group) $+\gamma_{B, 0}$

and $\Delta G_{1}=\Sigma \gamma_{1}$ (structural group) $+\gamma_{1,0}$

where $\gamma_{B}$ (structural group) and $\gamma_{1}$ (structural group) represent the structural group

contribution to the free energy of hydration of the solute molecule in the bulk solution phase and the membrane-solution interface respectively, and $\gamma_{B, 0}$ and $\gamma_{1}, 0$ are the corresponding characteristic constants common to all structural groups involved (Ref. 31 ). The values of $\gamma_{B}, \gamma_{B}, 0, \gamma_{1}$ and $\gamma_{1,0}$ for different structural groups applicable for cellulose acetate material-aqueous solution interfaces are listed in Table 2.

Steric parameter $\sum E_{S}$

The steric parameter $E_{S}$ for the substituent group in a polar organic molecule is defined by Taft as (Ref. 36):

$E_{s}=\log \left(k / k_{0}\right) A$

where $k$ and $k_{0}$ are the rate constants in the acidic hydrolysis of $\mathrm{RCOOR}^{\prime}$ and $\mathrm{CH}_{3} \mathrm{COOR}^{\prime}$

respectively. This definiton for $E_{S}$, which is related to his definition of $\sigma^{*}$, is based on the assumption that the susceptibility of acidic hydrolysis to polar effects is virtually zero. Though this assumption is not strictly true, and it is impossible to separate the polar and steric effects completely, Taft's values of $E_{s}$ (Ref. 36) are practically valid for the correlation of experimental reverse osmosis data (Ref. 38). The value of $E_{s}$ for the substituent group in the solute molecule depends only on the chemical structure of the group, and represents the property of the solute in the bulk solution phase. Just as $\sum \sigma \%$, a decrease in the value of $\sum E_{S}$ for the solute molecule yields a lower value of $D_{A M} / K \delta$, and hence higher solute separation in reverse osmosis under otherwise identical experimental conditions (Ref. 38).

\section{Nonpolar parameter $\Sigma s *$ for solute}

A direct measure of hydrophobicity, or nonpolar character of a hydrocarbon molecule is given either by its molar solubility in water or by its molar attraction constant as given by Small (Ref. 42). A decrease in solubility or increase in Small's number signifies an increase in hydrophobicity or nonpolar character for the hydrocarbon. The Small's number versus logarithm of solubility is a straight line which is different for different reactive series of compounds of similar chemical nature including paraffins, cycloparaffins, olefins, cycloolefins, diolefins, acetylenes and aromatics. By adjusting the data on Small's number for various structural groups such that the correlation of Small's number for the paraffin hydrocarbon (taken as reference) versus logarithm of its molar solubility in water is valid for hydrocarbons in all the above reactive series, a new nonpolar parameter called "modified Small's number" $(s *)$ has been obtained for different structural groups (Ref. 28) as given in Table 3. The nonpolar parameter $\Sigma s *$ for a hydrocarbon molecule or the hydrocarbon backbone of a polar organic molecule is obtained from its chemical structure using the additive 
TABLE 1. Free energy parameter $(-\Delta \Delta G / R T)$ for some ions and ion-pairs at $25^{\circ} \mathrm{C}$ for cellulose acetate membrane-aqueous solution interfaces (Ref. 30, 32-34)

\begin{tabular}{|c|c|c|c|c|c|}
\hline \multicolumn{2}{|c|}{ Species $\quad(-\Delta \Delta G / R T)$} & \multirow{2}{*}{$\frac{\text { Species }}{\mathrm{Br}^{-}}$} & $(-\Delta \Delta G / R T)$ & Species & \multirow[t]{2}{*}{$(-\Delta \Delta G / R T)$} \\
\hline Inorgan & cations & & -4.25 & Organic ions & \\
\hline$\overline{\mathrm{H}^{+}}$ & 6.34 & $1^{-}$ & -3.98 & $\mathrm{HCOO}^{-}$ & -4.78 \\
\hline $\mathrm{Li}^{+}$ & 5.77 & $10_{3}^{-}$ & -5.69 & H Phthalate & -4.63 \\
\hline $\mathrm{Na}^{+}$ & 5.79 & $\mathrm{H}_{2} \mathrm{PO}_{4}^{-}$ & -6.16 & $\mathrm{C}_{2} \mathrm{O}_{4}^{2-}$ & -14.06 \\
\hline $\mathrm{K}^{+}$ & 5.91 & $\mathrm{BrO}_{3}^{-}$ & -4.89 & $t-\mathrm{C}_{4}^{4} \mathrm{H}_{9} \mathrm{COO}_{-}^{-}$ & -6.90 \\
\hline $\mathrm{Rb}^{+}$ & 5.86 & $\mathrm{NO}_{2}^{-}$ & -3.85 & $i-\mathrm{C}_{3} \mathrm{H}_{7} \mathrm{COO}^{-}$ & -6.11 \\
\hline $\mathrm{Cs}^{+}$ & 5.72 & $\mathrm{NO}_{3}^{-}$ & -3.66 & cyclo- $\mathrm{C}_{6} \mathrm{H}_{11} \mathrm{COO}^{-}$ & -6.24 \\
\hline $\mathrm{NH}_{4}^{+}$ & 5.97 & $\mathrm{ClO}_{3}^{-}$ & -4.10 & $n-\mathrm{C}_{4} \mathrm{H}_{9} \mathrm{COO}^{-}$ & -6.11 \\
\hline $\mathrm{Mg}^{2+}$ & 8.72 & $\mathrm{ClO}_{4}^{-}$ & -3.60 & $n-\mathrm{C}_{3} \mathrm{H}_{7} \mathrm{COO}^{-}$ & -6.06 \\
\hline $\mathrm{Ca}^{2+}$ & 8.88 & $\mathrm{HCO}_{3}^{-}$ & -5.32 & $\mathrm{C}_{2} \mathrm{H}_{5} \mathrm{COO}^{-}$ & -6.14 \\
\hline $\mathrm{Sr}^{2+}$ & 8.76 & $\mathrm{HSO}_{4}^{-}$ & -6.21 & $\mathrm{CH}_{3} \mathrm{COO}^{-}$ & -5.95 \\
\hline $\mathrm{Ba}^{2+}$ & 8.50 & $\mathrm{SO}_{4}^{2-}$ & -13.20 & $\mathrm{C}_{6} \mathrm{H}_{5}\left(\mathrm{CH}_{3}\right)_{2} \mathrm{COO}^{-}$ & -5.93 \\
\hline $\mathrm{Mn}^{2+}$ & 8.58 & $\mathrm{~S}_{2} \mathrm{O}_{3}{ }^{2-}$ & -14.03 & $\mathrm{C}_{6} \mathrm{H}_{5}\left(\mathrm{CH}_{2}\right)_{2} \mathrm{COO}^{-}$ & -5.86 \\
\hline $\mathrm{Co}^{2+}$ & 8.76 & $\mathrm{SO}_{3}^{2-}$ & -13.12 & $\mathrm{C}_{6} \mathrm{H}_{5}\left(\mathrm{CH}_{2}\right) \mathrm{COO}^{-}$ & -5.69 \\
\hline $\mathrm{Ni}^{2+}$ & 8.47 & $\mathrm{CrO}_{4}{ }^{2-}$ & -13.69 & $\mathrm{C}_{6} \mathrm{H}_{5} \mathrm{COO}^{-}$ & -5.66 \\
\hline $\mathrm{Cu}^{2+}$ & 8.41 & $\mathrm{Cr}_{2} \mathrm{O}_{7}^{2-}$ & -11.16 & $p-\mathrm{CH}_{3} \mathrm{OC}_{6} \mathrm{H}_{4} \mathrm{COO}^{-}$ & -5.74 \\
\hline $\mathrm{Zn}^{2+}$ & 8.76 & $\mathrm{CO}_{3}^{2-}$ & -13.22 & $m-\mathrm{CH}_{3} \mathrm{C}_{6} \mathrm{H}_{4} \mathrm{COO}^{-}$ & -5.67 \\
\hline $\mathrm{Cd}^{2+}$ & 8.71 & $\mathrm{Fe}^{3}(\mathrm{CN}) 6^{3-}$ & -20.87 & $\mathrm{~m}-\mathrm{OHC}_{6} \mathrm{H}_{4} \mathrm{COO}^{-}$ & -5.64 \\
\hline $\mathrm{Pb}^{2+}$ & 8.40 & $\mathrm{Fe}(\mathrm{CN})_{6}^{4-}$ & -26.83 & $p-\mathrm{ClC}_{6} \mathrm{H}_{4} \mathrm{COO}^{-}$ & -5.63 \\
\hline $\mathrm{Fe}^{2+}$ & 9.33 & \multirow{2}{*}{\multicolumn{2}{|c|}{$\underline{\text { Inorganic ion-pairs }}$}} & $m-\mathrm{NO}_{2} \mathrm{C}_{6} \mathrm{H}_{4} \mathrm{COO}^{-}$ & -5.92 \\
\hline $\mathrm{Fe}^{3+}$ & 9.82 & & & $p-\mathrm{NO}_{2} \mathrm{C}_{6} \mathrm{H}_{4} \mathrm{COO}^{-}$ & -5.93 \\
\hline $\mathrm{Al}^{3+}$ & 10.41 & $\mathrm{CoSO}_{4}$ & $\begin{array}{l}3.45 \\
3.41\end{array}$ & $0-\mathrm{ClC}_{6} \mathrm{H}_{4} \mathrm{COO}^{-}$ & -6.41 \\
\hline $\mathrm{Ce}^{3+}$ & 10.62 & $\mathrm{ZnSO}_{4}$ & 2.46 & $\mathrm{O}-\mathrm{NO}_{2} \mathrm{C}_{6} \mathrm{H}_{4} \mathrm{COO}^{-}$ & -6.61 \\
\hline $\mathrm{Cr}^{3+}$ & $\begin{array}{l}11.28 \\
12.89\end{array}$ & $\mathrm{MnSO}_{4}$ & 2.48 & $\mathrm{HOOCCOO}^{-}$ & -6.60 \\
\hline $\mathrm{La}^{3+}$ & 12.89 & $\mathrm{CuSO}_{4}$ & 2.85 & $\mathrm{HOOCCH}_{2} \mathrm{COO}^{-}$ & -6.46 \\
\hline $\mathrm{Th}^{4+}$ & 12.42 & $\mathrm{CdSO}_{4}$ & 3.04 & $\mathrm{HOOC}\left(\mathrm{CH}_{2}\right){ }_{2} \mathrm{COO}^{-}$ & -5.65 \\
\hline \multicolumn{2}{|c|}{ Inorganic anions } & $\mathrm{NiSO}_{4}$ & 2.18 & $\mathrm{CH}_{3} \mathrm{CHOHCOO}^{-}$ & -6.30 \\
\hline $\mathrm{OH}^{-}$ & -6.18 & $\mathrm{KFe}(\mathrm{CN}) 6^{2-}$ & -2.53 & $\mathrm{HOOCCH}(\mathrm{OH}) \mathrm{CH}_{2} \mathrm{COO}^{-}$ & -5.97 \\
\hline $\mathrm{F}^{-}$ & -4.91 & $\mathrm{KFe}(\mathrm{CN}) 6^{3-}$ & -17.18 & $\mathrm{HOOCCH}(\mathrm{OH}) \mathrm{CH}(\mathrm{OH}) \mathrm{COO}^{-}$ & -6.40 \\
\hline $\mathrm{Cl}^{-}$ & -4.42 & & & $\mathrm{HOOCCH}_{2} \mathrm{C}(\mathrm{OH})(\mathrm{COOH}) \mathrm{CH}_{2} \mathrm{COO}^{-}$ & -6.24 \\
\hline
\end{tabular}

TABLE 2. Structural group contributions for $\Delta G_{B}$ and $\Delta G$, at $25^{\circ} \mathrm{C}$ for cellulose acetate membrane-aqueous solution interfaces (Ref. 31 )

\begin{tabular}{|c|c|c|c|c|c|}
\hline \multicolumn{6}{|c|}{$\gamma_{B, 0}=-12.04 ; \gamma_{1,0}=-41.21$} \\
\hline Structural group & $\gamma_{B}$ & $\gamma_{1}$ & Structural group & $\gamma_{B}$ & $\gamma_{1}$ \\
\hline$-\mathrm{CH}_{3}$ & 11.07 & 24.23 & $-\mathrm{CN}$ & 5.19 & 17.17 \\
\hline$>\mathrm{CH}_{2}$ & 0.17 & 0.24 & $>C=0$ & -5.80 & -6.32 \\
\hline$\rightarrow \mathrm{CH}^{2}$ & -10.62 & -23.65 & $-\mathrm{CHO}$ & 5.80 & 18.84 \\
\hline$>C<$. & -21.50 & -47.39 & $-\mathrm{COOH}$ & 2.49 & 15.13 \\
\hline Cyclic & 20.49 & 47.09 & $-\mathrm{NO}_{2}$ & 6.56 & 18.95 \\
\hline$-\mathrm{OH}^{\mathrm{a}}$ & 3.99 & 17.04 & $-\mathrm{CONH}_{2}$ & -0.21 & 12.75 \\
\hline$>0$ & -4.03 & -4.59 & $-\mathrm{C}_{6} \mathrm{H}_{5}$ & 8.41 & 21.43 \\
\hline
\end{tabular}

aFor exceptions, see Table 6 .

TABLE 3. Modified Small's number (nonpolar parameter $5 *$, in $c a l \frac{1}{2} \mathrm{~cm}_{\frac{3}{2}} \mathrm{~mol}^{-1}$ )

for some organic structural groups (Ref. 28)

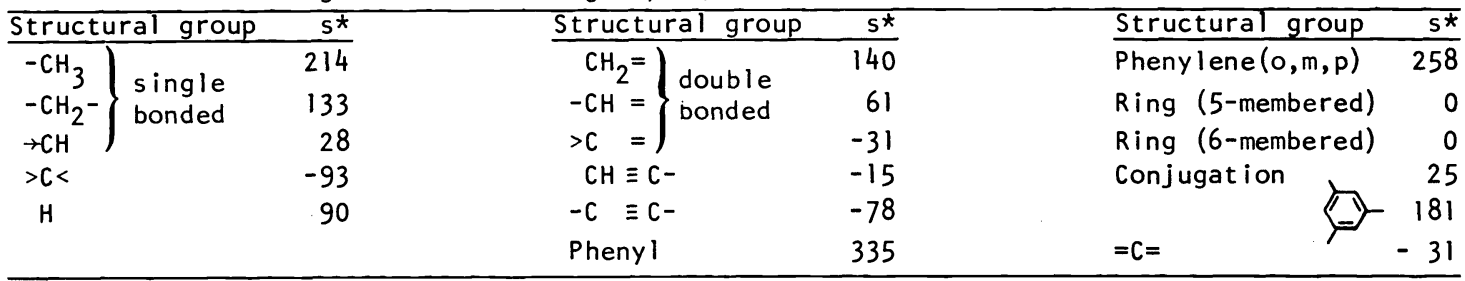


property of $s \%$ for different structural groups. The scale of $\Sigma s *$ is consistent within each of the groups of aromatic, cyclic and noncyclic hydrocarbon structure. Just as $\sum \sigma^{*}$ and $\sum E_{s}$, $\Sigma s *$ represents the property of the solute in the bulk solution phase. The numerical values of $\Sigma s *$ give a quantitative measure of the relative mutual attraction of organic molecules to one another as a result of dispersion forces. Thus with respect to aqueous solutions and cellulose acetate membranes, a higher value of $\Sigma s *$ signifies greater polymer-solute attraction resulting either in a decrease in preferential sorption of water or increase in preferential sorption of solute at the membrane-solution interface.

\section{MEMBRANES}

The materials science of reverse osmosis membranes is concerned with the physicochemical basis for the choice of $(i)$ the membrane material and ( $i i)$ the film casting conditions for the chosen membrane material, for use in a given reverse osmosis operation. Even though a large number of materials and membranes has been investigated, and their usefulness for reverse osmosis applications has been successfully demonstrated, very few fundamental studies on the materials science of reverse osmosis membranes have been reported in the literature.

Physicochemical basis for the choice of membrane material

Dielectric constants. Ions in aqueous solution are repelled in the vicinity of membrane materials of low dielectric constant by the so called electrical image forces arising at the membrane-solution interface. As a result of these repulsions, solute separations in reverse osmosis tend to increase with decrease in dielectric constant of the membrane material (Ref. $4,7,43)$. Consequently, data on dielectric constants offer a general basis for the choice of membrane material for reverse osmosis separation of ionized solutes in aqueous solutions.

Polar $\left(\alpha_{0}\right)$-, and nonpolar $\left(\alpha_{\eta}\right)$-parameters. Solute-solvent-column material interactions in liquid-solid chromatography ( $L S C$ ) may be considered to be analogous to the interactions prevailing at the membrane-solution interface in reverse osmosis. Therefore, LSC data on retention time $(t)$ ratios $\left(r_{1}\right.$ and $\left.r_{2}\right)$ for a set of suitably chosen reference solutes $s_{1}$ and s2 in aqueous solutions in chromatographic columns containing different materials, offer a useful basis for the choice of such materials for making reverse osmosis membranes.

Using different polymeric materials in the chromatographic columns, and benzyl alcohol (benz alc), phenol, and phenethyl alcohol (phen alc) as the reference solutes and potassium biphthalate as the unretained component (uc), and assuming that the free energy change in the adsorption equilibrium in LSC is a linear function of the polar-, and nonpolar-character of each of the solute and polymer material involved, the following relationships have been derived for the $\alpha_{p^{-}}$and $\alpha_{n}$-parameters representing the polar (hydrogen bonding) and nonpolar (hydrophobic) characters respectively of the polymer material (Ref. 44):

$\alpha_{p}=0.812\left(\ln r_{1}-\ln r_{2}\right)$

and $\alpha_{n}=0.188 \ln r_{1}+0.812 \ln r_{2}$

where $r_{1}=\left(t_{\text {benz alc }}-t_{u c}\right) /\left(t_{\text {phenol }}-t_{u c}\right)=K_{\text {benz alc }} / K_{\text {phenol }}$

and $\quad r_{2}=\left(t_{\text {phen alc }}-t_{u c}\right) /\left(t_{\text {benz alc }}-t_{u c}\right)=K_{\text {phen alc }} / K_{\text {benz alc }}$

The quantities $\ln r_{1}$ and $\ln r_{2}$ represent the differences in free energy changes in the adsorption equilibriums for the solutes $s_{1}$ and $s_{2}$ involved. The constants in Eqs. 6 and 7 arise from the choice of the reference solutes and the arbitrary units chosen to represent the polar and nonpolar characters for the solute molecules involved. In Eqs. 8 and 9 , the values of $t$ are at constant solvent flow rate. The values of $\alpha_{p}$ and $\alpha_{n}$ for a number of polymer materials are given in Table 4.

The values of $\alpha_{p}$ and $\alpha_{n}$ are higher for the aromatic polyamide materials than for the cellulose acetate material. Reverse osmosis data show that solute separations for polar organics are higher with the aromatic polyamide membranes than with cellulose acetate membranes with comparable average size of pores on the membrane surface (Ref. 45 ). These results indicate that, with the same average pore size on the membrane surface, reverse osmosis separations for polar organic solutes can be expected to be relatively higher with membranes made from materials whose $\alpha_{p}$ and $\alpha_{n}$ values are higher.

Further, the nonpolar (hydrophobic) force of the polymer material, besides being an attractive force for the organic solute, has an additional effect on reverse osmosis transport. An increase in the value of $\alpha_{n}$ tends to increase the mobility of the preferentially sorbed water through the membrane pores when water is preferentially sorbed, and to decrease the mobility of the solute when the latter is preferentially sorbed. Both these effects contribute to higher solute separation in reverse osmosis. Higher separations for organics obtainable with aromatic polyamide membranes than with comparable cellulose acetate membranes is understandable simply on the basis of their relative $\alpha_{n}$ values. On the basis 
of this guideline, one may expect relatively higher separations for organics with more nonpolar cellulosic membranes also. This is confirmed experimentally by the results obtained with cellulose acetate propionate membranes (Ref. 46).

B-parameters. Using t-butyl alcohol, s-butyl alcohol, sodium thiocyanate and raffinose as the arbitrarily chosen reference solutes in LSC, several polymer materials have been characterized (Table 4) by a parameter called the $\beta$-parameter, defined as follows (Ref. 47):

$\beta=\left(\ln r_{1}+\ln r_{2}\right) / 2$

where $r_{1}=\left(t_{\mathrm{t}-\mathrm{BuOH}}-t_{\text {raffinose }}\right) /\left(t_{\mathrm{NaSCN}}-t_{\text {raffinose }}\right)$

and $r_{2}=\left(t_{s-B u O H}-t_{\text {raffinose }}\right) /\left(t_{\mathrm{NaSCN}}-t_{\text {raffinose }}\right)$

Again, in Eqs. 11 and 12 the values of t are at constant solvent flow rate. By virtue of the choice of the reference solutes, the $\beta$-parameter may be expected to be sensitive to both the polar and the nonpolar characters of the polymer molecule involved. The values of $\beta$ exhibit unique correlations with the other parameters governing solute separations in reverse osmosis systems where water is preferentially sorbed at the membrane-solution interface (Ref. 47). From such correlations, the values of $\gamma_{1}$ (structural group) and $\gamma_{1,0}$ (Eq. 4) as well as those of $-\triangle \Delta G / R T$ for $\mathrm{Na}^{+}$and $\mathrm{Cl}^{-}$ions have been obtained for different polymeric materials as a function of their $\beta$-parameters as given in Tables 5 and 6 . These data, along with the other correlations presented later in this paper (Fig. 3), make the $\beta$-parameters a useful physicochemical basis for the choice of reverse osmosis membrane material.

\section{Physicochemical basis for the choice of film casting conditions}

A fundamental understanding of the mechanism of pore formation and development in the process of making asymmetric porous membranes should be the physicochemical basis for the choice of film casting conditions for use in a given reverse osmosis operation. Even though there are several reports on the subject (Ref. 48-57) a comprehensive understanding of the above mechanism applicable to different kinds of membrane-materials, membrane-configurations and membranes of different pore structures, has not yet emerged. However with respect to the development of asymmetric porous cellulose acetate flat and tubular membranes, the following statements can be made (Ref. 58-75).

Basic steps in film casting operation. The film casting solution is usually a mixture of the polymer P (e.g., cellulose acetate), a solvent S (e.g., acetone), and an essentially nonsolvent swelling agent $N$ (e.g., aqueous solution of magnesium perchlorate, or formamide). The film making procedure involves generally the following steps: (i) casting the polymer solution as a thin film on a surface, ( $i i$ ) evaporation (or removal) of solvent from the surface, $(\mathrm{i} i \mathrm{i})$ immersion of the $\mathrm{film}$ in an appropriate gelation medium such as cold water or an aqueous ethanol solution, and finally (iv) thermal shrinking, pressurization and/or other membrane pretreatment techniques. Each one of the above steps is important because each affects the ultimate porous structure of the entire membrane and hence its subsequent performance in reverse osmosis.

Mechanism of pore formation and development. Following Kesting (Ref. 51, 52), the development of asymmetric porous structure in the membrane may be described briefly as follows. Immediately after casting, solvent evaporation starts at the air-solution interface. As a result of solvent loss, a cloud point in the surface region is reached when droplets of the swelling agent separate from the solution as a second interdispersed phase with the polymer molecules concentrated at the exterior surface of the droptlets. On continued desolvation, the droplets in the surface region contact one another forming polyhedra whose number, size and wall thickness depend on polymer structure in the casting solution and on desolvation conditions. The subsequent immersion of the polymer film in the gelation medium accelerates and completes the desolvation process both in the surface layer and in the bulk region underneath. During the desolvation process, the walls of the polyhedra rupture, and closed cells give way to more numerous open cells which, together with voids between cells, give rise to a microporous surface structure. In the interior bulk region of the film, the polymer molecules aggregate and precipitate rapidly giving rise to a spongy porous mass underneath the surface, and hence a completely open celled asymmetric porous structure for the entire membrane.

Solution structure-evaporation rate approach to membrane development. The above picture of phase separation and pore formation during film casting, though still incomplete, has led to a definite physicochemical approach for the choice of film casting conditions. In this approach, the state or the structure of the casting solution and the rate of solvent evaporation during film formation together constitute an important interconnected variable governing the ultimate porous structure and hence the performance of the resulting membrane in reverse osmosis. The structure of the casting solution is a function of $i$ ts composition and temperature. Solvent evaporation rate during film formation is a function of solution structure, temperature of casting atmosphere and the ambient nature of casting atmosphere. 
TABLE 4. Characterization of some polymers for use as reverse osmosis membrane materials

\begin{tabular}{|c|c|c|c|c|c|}
\hline No. & Polymer & Source & $\alpha_{p}$ & $\alpha_{n}$ & $\beta$ \\
\hline $\begin{array}{r}23 \\
20 \\
17 \\
22 \\
6 \\
34 \\
9 \\
2\end{array}$ & $\begin{array}{l}\text { Aromatic copolyamido-hydrazide, PPPH } 8273 \\
\text { Aromatic copolyamido-hydrazide, PPPH } 1115 \\
\text { Aromatic copolyamide } \\
\text { Aromatic copolyhydrazide } \\
\text { Cellulose acetate propionate, acetyl } \\
\text { content, } 30.6 \% \text {; propionyl content, } 14.5 \% \\
\text { Ethyl cellulose phthalate } \\
\text { Cellulose acetate butyrate, } 171-40 \\
\text { Cellulose acetate, } 398-3\end{array}$ & $\begin{array}{l}\text { Lab made } e^{a} \\
\text { Lab made } \\
\text { Lab made } \\
\text { Lab made } \\
K \text { \& } K \text { Lab } \\
\text { Jamaica, N.Y. } \\
\text { Eastman } \\
\text { Eastman } \\
\text { Eastman }\end{array}$ & $\begin{array}{l}-0.31 \\
-0.22 \\
-0.43 \\
-0.54 \\
-1.33 \\
-1.28 \\
-1.00\end{array}$ & $\begin{array}{l}0.144 \\
0.149 \\
0.259 \\
0.041 \\
0.143 \\
- \\
-0.377 \\
-0.017\end{array}$ & $\begin{array}{l}0.17 \\
0.20 \\
0.46 \\
0.67 \\
0.74 \\
1.16 \\
1.26 \\
1.37\end{array}$ \\
\hline
\end{tabular}

Notes on polymers:

aromatic copolyamidohydrazide PPPH 8273<smiles>CC(C)(C)NC(=O)c1ccc(NC(=O)N2CC2)cc1</smiles>

8070 mole $\%$ meta $20 \quad 30$ mole \% para

aromatic copolyamidohydrazide, PPPH 1115<smiles>CC(C)(C)Nc1ccc(O)cc1</smiles>

where $R$ represents a random distribution of

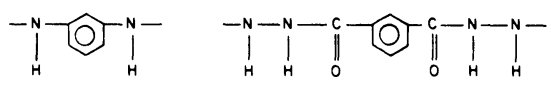

in the mole ratio of $1.54: 0.46$ aromatic copolyamide (17)

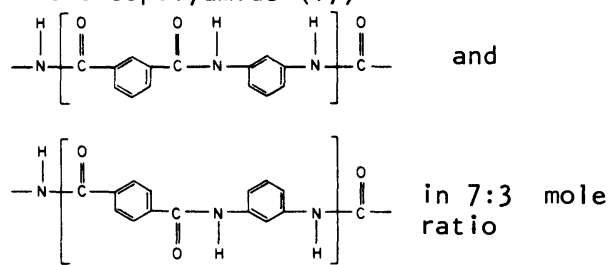

aromatic copolyhydrazide (22), a random copolymer consisting of an equimolar ratio of the following repeat units

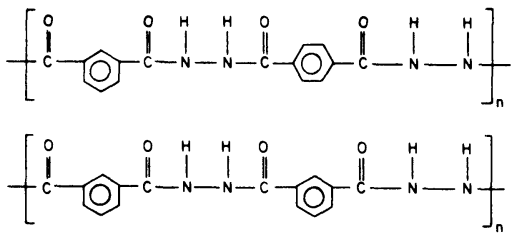
and

TABLE 5. Combined- $\gamma$, values as a function of $\beta$-parameter for polymer materials (Ref. 47)

\begin{tabular}{|c|c|c|c|c|c|c|c|c|c|}
\hline \multirow[b]{2}{*}{$\begin{array}{l}\text { Polymer } \\
\text { number }\end{array}$} & \multirow[b]{2}{*}{$\beta$} & \multicolumn{8}{|c|}{ Combined $-\gamma_{1}$ values } \\
\hline & & $\begin{aligned} & 2 \gamma_{1}\left(-\mathrm{CH}_{3}\right) \\
&+ \gamma_{1,0} \\
&\end{aligned}$ & $\gamma_{1}\left(>\mathrm{CH}_{2}\right)$ & $\begin{array}{l}\gamma_{1}(\rightarrow \mathrm{CH})+ \\
\gamma_{1}\left(-\mathrm{CH}_{3}\right)\end{array}$ & $\begin{array}{l}\gamma_{1}(>\mathrm{C}<)+ \\
2 \gamma_{1}\left(-\mathrm{CH}_{3}\right)\end{array}$ & $\begin{array}{l}\gamma_{1}(-\mathrm{OH}) \\
-\gamma_{1}\left(-\mathrm{CH}_{3}\right)\end{array}$ & $\gamma_{1}(>0)$ & $\gamma_{1}(>c=0)$ & $\begin{array}{l}\gamma_{1}(-\mathrm{CHO}) \\
-\gamma_{1}\left(-\mathrm{CH}_{3}\right)\end{array}$ \\
\hline $\begin{array}{r}23 \\
20 \\
17 \\
22 \\
6 \\
34 \\
9 \\
2\end{array}$ & $\begin{array}{l}0.17 \\
0.20 \\
0.46 \\
0.67 \\
0.74 \\
1.16 \\
1.26 \\
1.37\end{array}$ & $\begin{array}{l}8.43 \\
8.41 \\
8.23 \\
8.06 \\
8.00 \\
7.51 \\
7.39 \\
7.25\end{array}$ & $\begin{array}{l}0.31 \\
0.31 \\
0.30 \\
0.30 \\
0.30 \\
0.28 \\
0.28 \\
0.24\end{array}$ & $\begin{array}{l}0.65 \\
0.65 \\
0.61 \\
0.61 \\
0.61 \\
0.59 \\
0.59 \\
0.58\end{array}$ & $\begin{array}{l}0.92 \\
0.92 \\
0.96 \\
1.00 \\
1.00 \\
1.04 \\
1.06 \\
1.07\end{array}$ & $\begin{array}{l}-7.41 \\
-7.39 \\
-7.11 \\
-7.08 \\
-7.07 \\
-7.11 \\
-7.17 \\
-7.19\end{array}$ & $\begin{array}{l}-4.38 \\
-4.30 \\
-3.86 \\
-3.79 \\
-3.80 \\
-4.20 \\
-4.40 \\
-4.60\end{array}$ & $\begin{array}{l}-5.95 \\
-5.94 \\
-5.89 \\
-5.90 \\
-5.93 \\
-6.20 \\
-6.25 \\
-6.32\end{array}$ & $\begin{array}{l}-5.55 \\
-5.51 \\
-5.31 \\
-5.30 \\
-5.32 \\
-5.35 \\
-5.38 \\
-5.39\end{array}$ \\
\hline
\end{tabular}

$1 / R T$ at $25^{\circ} \mathrm{C}=0.5925 \mathrm{~mol} / \mathrm{kcal}$

With reference to a given casting solution, its temperature and that of the casting atmosphere (together with the ambient nature of the casting atmosphere) are two separate variables in the specification of the film casting conditions; by appropriate choice of these two variables alone, the productivity (i.e., product rate at a given level of solute separation) of resulting membranes can be changed and improved. The "structure" of the casting solution essentially refers to the size of supermolecular polymer aggregates in it. No quantitative parameter to specify the casting solution structure is currently available. Solvent evaporation rate however can be measured experimentally.

Some major conclusions. Smaller size of polymer aggregates in the casting solution tends to create a larger number of smaller size nonsolvent droplets in the interdispersed phase, resulting ultimately in larger number of smaller size pores on the membrane surface. Since higher droplet density favors droplet-coalescence, there is an optimum size of polymer aggregate in the casting solution for maximum productivity of resulting membranes. The size 
TABLE 6. Some values of $-\triangle \Delta G / R T$ as a function of B-parameter for polymer materials (Ref. 47)

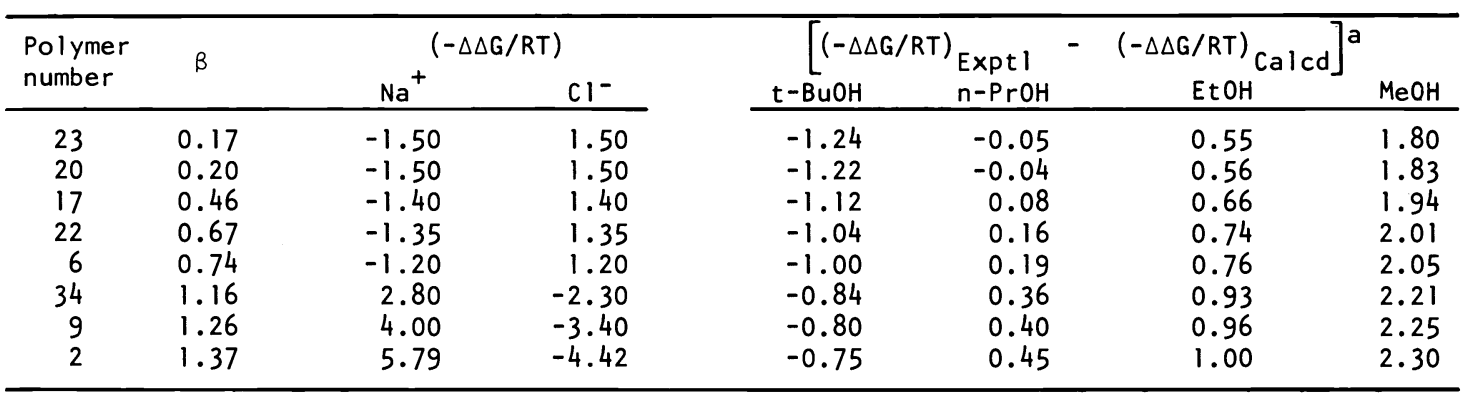

${ }^{a}(-\Delta \Delta G / R T)_{C a l c d}$ refers to $(-\Delta \Delta G / R T)$ values calculated by using the $\gamma_{\text {, values given in }}$

Table 5. The values of $(-\Delta \Delta G / R T)_{\text {Exptl }}$ are the ones to be used for predicting membrane performance.

of the supermolecular polymer aggregate in the casting solution is decreased by (a) increasing solvent/polymer (S/P) ratio, (b) decreasing nonsolvent/solvent (N/S) ratio, and (c) increasing the temperature of the casting solution. The solvent evaporation rate during film formation increases with increase in the temperature of the casting solution and that of the casting atmosphere. High solvent evaporation rate favors both droplet-formation and dropletcoalescence. Since these two events have opposing effects on the size and number of resulting pores on the membrane surface, the solvent evaporation rate should be high enough to generate the largest number of interdispersed droplets, and low enough to prevent excessive droplet-coalescence. Therefore, for each casting solution structure, there exists an optimum evaporation rate for maximum membrane productivity. A given casting solution structure-evaporation rate combination (how so ever it is achieved) results in membranes of identical productivity provided their shrinkage temperature profiles (representing pore size distribution on the membrane surface) are the same. Gelation control is an effective means of changing pore size, and pore size distribution on the membrane surface; this technique is particularly useful for making the so-called ultrafilter membranes. On the basis of the foregoing conclusions, significant improvements in the productivity of cellulose acetate reverse osmosis membranes of different surface porosities have been accomplished (Ref. 73,75$)$.

\section{TRANSPORT}

The engineering science of reverse osmosis transport is concerned with the development of basic equations governing such transport, and the integration of the physicochemical parameters governing separations into the above equations leading to precise analytical techniques of membrane specification, prediction of membrane performance, system analysis and process design. With respect to reverse osmosis systems involving aqueous solutions and preferential sorption of water at the membrane solution interface, such transport equations have been developed as follows.

\section{Basic reverse osmosis transport equations}

At any given operating temperature and pressure, the experimental reverse osmosis data on pure water permeation rate $(P W P)$, product rate $(P R)$ and fraction solute separation $f$ at any point in the reverse osmosis system can be analyzed on the basis that (PWP) is directly proportional to the operating pressure, the solvent water transport $\left(N_{B}\right)$ through the membrane is proportional to the effective pressure, the solute transport $\left(N_{A}\right)$ through the membrane is due to pore diffusion through the membrane capillaries and hence proportional to the concentration difference across the membrane, and the mass transfer coefficient $k$ on the high pressure side of the membrane is given by the " $\mathrm{fi} / \mathrm{m}$ " theory on mass transport. This analysis, which is applicable to all membrane materials and membranes at all levels of solute separation, gives rise to the following basic reverse osmosis transport equations (Ref. 1, 76):

$A=(P W P) / M_{B} \times S \times 3600 \times P$

$N_{B}=A\left[P-\pi\left(X_{A 2}\right)+\pi\left(X_{A 3}\right)\right]$

$=\left(\frac{{ }_{A M}}{K \delta}\right)\left(\frac{1-x_{A 3}}{X_{A 3}}\right)\left(c_{2} x_{A 2}-c_{3} X_{A 3}\right)$

$=k_{1}\left(1-x_{A 3}\right) \ln \left(\frac{x_{A 2}-x_{A 3}}{x_{A 1}-x_{A 3}}\right)$ 
All symbols are defined at the end of the paper. In this analysis, the low pressure side of the membrane is assumed to be at atmospheric pressure, and the operating pressure $P$ is given in gauge pressure. The subscripts 1, 2, and 3 refer to bulk solution phase and concentrated boundary solution phase on the high pressure side of the membrane, and the product solution phase on the low pressure side of the membrane respectively.

Equation 13 defines the pure water permeability constant $A$ which is a fundamental quantity with respect to the membrane. The quantity $A$ is a measure of the overall porosity of the membrane; it represents pure water transport in the absence of any concentration polarization (datum condition) on the high pressure side of the membrane. The magnitude of $A$ is independent of any solute under consideration.

Equation 14 is valid when the viscosity of the membrane permeated product solution is essentially the same as that of pure water. This approximation is justified in most cases of practical interest. Equation 14 enables cne to calculate the concentration $X_{A 2}$ of the boundary solution on the high pressure side of the membrane under the reverse osmosis operating conditions. When the concentration $X_{A} 3^{-}$of the membrane permeated product solution on the low pressure side of the membrane is less than the concentration $X_{A}$ of the bulk feed solution on the high pressure side of the membrane, $X_{A 2}$ is greater than $X_{A 1}$.

Equation 15 defines the parameter $D_{A M} / K \delta$ expressing solute transport through the membrane. The solute transport parameter $D_{A M} / K \delta$ is a fundamental quantity for any given membranesolution system. The above quantity is not a mere proportionality constant; it is a combination of at least three distinct quantities - the solute diffusivity through the membrane $D_{A M}$, the effective film thickness $\delta$, and the equilibrium constant $K$ relating solute concentration in the membrane phase and that in the solution phase in equilibrium with the membrane phase - all of which have important physical significance, but none of which can be precisely measured. From the point of view of the engineering science of reverse osmosis transport, it is sufficient to know the overall value of the parameter $D_{A M} / K \delta$ which plays the role of a mass transfer coefficient with respect to solute transport through the membrane. Hence this parameter is treated as a single quantity for purposes of analysis.

Equation 16 enables one to calculate the mass transfer coefficient $k$ on the high pressure side of the membrane. The magnitude of $k$ is a function of the nature of solute, concentration of feed solution, feed flow rate, porosity of the membrane and the geometry of the apparatus used. For any given apparatus and membrane-solution-operating system, the relationship between feed flow rate and $k$ is needed for process design. This information can be obtained experimentally or, in some cases, analytically (Ref. 77). In any case, the feed flow condition on the high pressure side of the membrane is best described in terms of the obtainable or required value of $k$ under the other specified operating conditions.

Under steady state operating conditions, a single set of experimental data on $(P W P)$, $(P R)$ and $f$ enables one to calculate the quantities $A, X_{A 2}, D_{A M} / K \delta$, and $k$ at any point (position or time) in the reverse osmosis system using Eqs. 13 to 16.

It must be emphasized that neither any one equation in the set of Eqs. 13 to 16 , nor any part of this set of equations, is adequate representation of reverse osmosis transport; the latter is governed simultaneously by the entire set of Eqs. 13 to 16 .

Correlations of experimental reverse osmosis data

The correlations of the quantities $A, D_{A M} / K \delta$ and $k$ with operating pressure, temperature, feed concentration, feed flow rate, nature of solute and membrane compaction during continuous operation are of practical interest from the point of view of specifying membranes and predicting membrane performance under different experimental conditions. Such correlations have to be established experimentally (Ref. 76-84) for different membrane materials, membranes, and solutes. The basic transport Eqs. 13 to 16, by themselves, are independent of such correlations. In the following discussion, unless otherwise specified, it is assumed that for a given membrane at any specified operating temperature and pressure, the value of $D_{A M} / K \delta$ for a given solute is independent of feed concentration, feed flow rate and membrane compaction. This correlation is valid for many organic and inorganic solutes including sodium chloride, with respect to cellulose acetate membranes of stable surface pore structure.

\section{Membrane specifications}

At a specified operating temperature and pressure, a membrane is completely specified in terms of $i$ ts pure water permeability constant $A$ and solute transport parameter $D_{A M} / K \delta$ for $a$ convenient reference solute. For the purpose of this paper, $\mathrm{NaCl}$ is used as the reference solute, so that a membrane is specified in terms of $A$ and $\left(D_{A M} / K \delta\right)_{N a C l}$. A single set of experimental data on $(P W P),(P R)$, and $f$ at known operating conditions is enough to obtain data on $A$ and $\left(D_{A M} / K \delta\right)_{N a C i}$. 


\section{Prediction of membrane performance}

Combining Eqs. 14, 15, and 16 .

$A\left[P-\pi\left(X_{A 2}\right)+\pi\left(X_{A 3}\right)\right]=\left(\frac{D_{A M}}{K \delta}\right)\left(\frac{1-X_{A 3}}{X_{A 3}}\right)\left(c_{2} X_{A 2}-c_{3} X_{A 3}\right)$

$\frac{\left(c_{2} X_{A 2}-c_{3} X_{A 3}\right)}{X_{A 3}}=\frac{k}{\left(D_{A M} / K \delta\right)} \quad c_{1} \ln \left(\frac{X_{A 2}-X_{A 3}}{X_{A 1}-X_{A 3}}\right)$

For a membrane specified in terms of $A$ and $D_{A M} / K \delta$, Eqs. 17 and 18 enable one to predict membrane performance (solute separation and membrane flux) for any feed concentration $X_{A}$, and any chosen feed flow condition specified in terms of $k$ as follows. First determine, by trial and error, the particular combination of $X_{A 2}$ and $X_{A 3}$ which simultaneously satisfies Eqs. 17 and 18. Using that combination of $X_{A 2}$ and $X_{A 3}$ values, determine $N_{B}$ from Eq. 14 . The above values of $X_{A 3}$ and $N_{B}$ give the obtainable solute separation and membrane flux which may be expressed in terms of $f$ and $(P R)$ respectively as follows:

$f=\frac{m_{1}-m_{2}}{m_{1}}=1-\left(\frac{x_{A 3}}{1-x_{A 3}}\right)\left(\frac{1-x_{A 1}}{x_{A 1}}\right) \approx 1-\frac{x_{A 3}}{x_{A 1}}$

$(P R)=\frac{N_{B} \times M_{B} \times S \times 3600}{\left[1-\frac{1}{\left(1+\frac{1000}{m_{1}(1-f) M_{A}}\right)}\right]} \mathrm{g} / \mathrm{h}$.

Using the above prediction procedure, one can calculate, for example, the effect of feed concentration, feed flow rate as expressed by $k$ and membrane compaction as expressed by A-factor (= value of $A$ at any time/initial value of $A$ ), on solute separation and product rate. A set of results of such calculations is illustrated in Tables 7 and 8 . The foregoing prediction procedure and the illustrative results show that while data on $A$ and $D_{A M} / K \delta$ are enough to specify a membrane, they are not enough to predict membrane performance for any feed concentration and feed flow rate; for such prediction, the applicable value of $k$ is needed in addition to the data on $A$ and $D_{A M} / K \delta$.

\section{System specification}

In any reverse osmosis process, the membrane-solution-operating system may be specified by three fundamental nondimensional parameters $\gamma, \theta$ and $\lambda$ defined as follows:

$\gamma=\frac{\pi\left(X_{A 1}^{O}\right)}{P}=\frac{\text { osmotic pressure of initial feed solution }}{\text { operating pressure }}$

$\theta=\frac{\left(D_{A M} / K \delta\right)}{v_{w}^{*}}=\frac{\text { solute transport parameter }}{\text { pure water permeation velocity }}$

$\lambda=\frac{k}{\left(D_{A M} / K \delta\right)}=\frac{\text { mass transfer coefficient on the high pressure side of membrane }}{\text { solute transport parameter }}$

The quantity $v_{W}^{*}$ is obtained from the relation

$v_{w}^{*}=\frac{A P}{c}$

and the quantity $\pi\left(X_{A}^{0}\right)$ refers to the osmotic pressure of the feed solution at membrane entrance in a flow process or start of operation in a batch process. The quantities $\gamma, \theta$ and $\lambda \theta\left(=k / v_{w}^{*}\right)$ may be described as the osmotic pressure characteristic, membrane characteristic and the mass transfer coefficient characteristic respectively for the reverse osmosis system under consideration. The significance of system specification is that a single set of numerical parameters can represent an infinite number of membrane-solution-operating systems; conversely, any two membrane-solution-operating systems can be simply and precisely differentiated in terms of unique combinations of numerical parameters.

System analysis and prediction of system performance

The transport Eqs. 13 to 16 offer a basis for the analysis of any reverse osmosis system. This is illustrated below with particular reference to reverse osmosis water treatment systems for which the following assumptions are practically valid: (i) the molar density 
TABLE 7. Effect of feed concentration and mass transfer coefficient $k$ on the performance of a cellulose acetate membrane with $\mathrm{NaCl}-\mathrm{H}_{2} \mathrm{O}$ feed solutions

\begin{tabular}{|c|c|c|c|c|c|c|c|c|c|c|}
\hline \multicolumn{2}{|c|}{ Feed Concn } & \multicolumn{9}{|c|}{$\mathrm{k} \times 10^{4} \mathrm{~cm} / \mathrm{s}$} \\
\hline Molality & $\begin{array}{r}\mathrm{Wt} . \% \\
\mathrm{NaCl}\end{array}$ & 10 & 20 & 30 & 40 & 50 & 75 & 100 & 150 & 200 \\
\hline & & \multicolumn{9}{|c|}{ Solute separation, \% } \\
\hline $\begin{array}{l}0.1 \\
0.2 \\
0.3 \\
0.4 \\
0.6 \\
0.8 \\
1.0\end{array}$ & $\begin{array}{l}0.581 \\
1.156 \\
1.723 \\
2.285 \\
3.388 \\
4.467 \\
5.522\end{array}$ & $\begin{array}{l}96.6 \\
96.6 \\
96.5 \\
96.4 \\
95.9 \\
95.1 \\
93.7 \\
\end{array}$ & $\begin{array}{l}98.1 \\
98.0 \\
97.8 \\
97.7 \\
97.3 \\
96.6 \\
95.5\end{array}$ & $\begin{array}{l}98.4 \\
98.3 \\
98.2 \\
98.1 \\
97.7 \\
97.1 \\
96.1 \\
\end{array}$ & $\begin{array}{l}98.6 \\
98.5 \\
98.4 \\
98.2 \\
97.9 \\
97.4 \\
96.4 \\
\end{array}$ & $\begin{array}{l}98.7 \\
98.6 \\
98.5 \\
98.3 \\
98.0 \\
97.5 \\
96.6\end{array}$ & $\begin{array}{l}98.8 \\
98.7 \\
98.6 \\
98.5 \\
98.2 \\
97.7 \\
96.9\end{array}$ & $\begin{array}{l}98.8 \\
98.8 \\
98.7 \\
98.5 \\
98.2 \\
97.8 \\
97.0\end{array}$ & $\begin{array}{l}98.9 \\
98.8 \\
98.7 \\
98.6 \\
98.3 \\
97.9 \\
97.1\end{array}$ & $\begin{array}{l}98.9 \\
98.8 \\
98.7 \\
98.6 \\
98.3 \\
97.9 \\
97.2\end{array}$ \\
\hline $\begin{array}{l}0.1 \\
0.2 \\
0.3 \\
0.4 \\
0.6 \\
0.8 \\
1.0 \\
\end{array}$ & $\begin{array}{l}0.581 \\
1.156 \\
1.723 \\
2.285 \\
3.388 \\
4.467 \\
5.522 \\
\end{array}$ & $\begin{array}{r}29.9 \\
25.0 \\
21.3 \\
18.3 \\
13.5 \\
9.7 \\
6.7 \\
\end{array}$ & $\begin{array}{r}32.6 \\
28.8 \\
25.5 \\
22.5 \\
17.2 \\
12.7 \\
8.8 \\
\end{array}$ & $\begin{array}{c}\text { Produc } \\
33.2 \\
29.9 \\
26.9 \\
24.1 \\
18.7 \\
14.0 \\
9.8 \\
\end{array}$ & $\begin{array}{l}\text { rate, } \\
33.6 \\
30.6 \\
27.7 \\
24.8 \\
19.7 \\
14.8 \\
10.4 \\
\end{array}$ & $\begin{array}{l}\mathrm{h} / 13.2 \\
33.8 \\
30.8 \\
28.1 \\
25.4 \\
20.2 \\
15.4 \\
10.8 \\
\end{array}$ & $\begin{array}{l}\mathrm{m}^{2} \text { of } \\
34.1 \\
31.3 \\
28.6 \\
26.0 \\
20.9 \\
16.0 \\
11.4 \\
\end{array}$ & $\begin{array}{c}1 \mathrm{~m} \text { are } \\
34.2 \\
31.5 \\
28.9 \\
26.4 \\
21.3 \\
16.4 \\
11.7 \\
\end{array}$ & $\begin{array}{l}34.2 \\
31.6 \\
29.2 \\
26.6 \\
21.7 \\
16.8 \\
12.1 \\
\end{array}$ & $\begin{array}{l}34.3 \\
31.8 \\
29.3 \\
26.8 \\
21.9 \\
17.0 \\
12.2\end{array}$ \\
\hline
\end{tabular}

Membrane specification: $A=1.10 \times 10^{-6} \mathrm{~mol} \mathrm{H}_{2} \mathrm{O} / \mathrm{cm}^{2} \mathrm{~s}$ atm, and $\left(\mathrm{D}_{\mathrm{AM}} / \mathrm{K \delta}\right)_{\mathrm{NaCl}}=1.31 \times 10^{-5}$ $\mathrm{cm} / \mathrm{s}$. Operating pressure, 1000 psig.

TABLE 8. Effect of membrane compaction (A-factor) on the performance of a cellulose acetate membrane with a $\mathrm{NaCl}-\mathrm{H}_{2} \mathrm{O}$ feed solution

\begin{tabular}{|c|c|c|}
\hline A-factor & Solute sepn, \% & Product rate, $\mathrm{g} / \mathrm{h}$ \\
\hline 1.0 & 96.6 & 10.8 \\
\hline 0.9 & 96.4 & 10.0 \\
\hline 0.8 & 96.0 & 9.1 \\
\hline 0.7 & 95.6 & 8.1 \\
\hline 0.6 & 95.1 & 7.2 \\
\hline 0.5 & 94.4 & 6.2 \\
\hline 0.4 & 93.4 & 5.1 \\
\hline 0.3 & 91.8 & 4.0 \\
\hline $\begin{array}{l}\text { Membrane } \\
\mathrm{cm}^{2} \mathrm{~s} \text { atr } \\
\text { Operating } \\
\text { and film }\end{array}$ & $\begin{array}{l}\text { ions: } \quad A=1 \\
A M / K o) \mathrm{NaCl}=1 \\
, 1000 \mathrm{psig} ; \\
2 \mathrm{~cm}^{2} .\end{array}$ & $\begin{array}{l}\times 10^{-6} \mathrm{~mol} \mathrm{H}_{2} \mathrm{O} \\
\times 10^{-5} \mathrm{~cm} / \mathrm{s} \\
\text { molality, } 1.0 ;\end{array}$ \\
\hline
\end{tabular}

TABLE 9. Performance data for a reverse osmosis system specified in terms of $\gamma, \theta$ and $\lambda \theta$

System specifications: $\gamma=0.264, \theta=0.012$ and $\lambda \theta$ as indicated

\begin{tabular}{|c|c|c|c|c|c|c|c|c|c|c|}
\hline \multirow{2}{*}{$\Delta$} & \multicolumn{4}{|c|}{$\lambda \theta=2$} & \multirow[b]{2}{*}{ cor $X$} & \multicolumn{5}{|c|}{$\lambda \theta=5$} \\
\hline & $c_{1}$ & $c_{2}$ & $c_{3}$ & $\bar{c}_{3}$ & & $c_{1}$ & $c_{2}$ & $c_{3}$ & $\bar{c}_{3}$ & $\tau$ or $X$ \\
\hline 0 & 1.000 & 1.368 & 0.021 & 0.021 & 0 & 1.000 & 1.147 & 0.016 & 0.016 & 0 \\
\hline 0.1 & 1.109 & 1.493 & 0.024 & 0.023 & 0.161 & 1.109 & 1.265 & 0.019 & 0.017 & 0.147 \\
\hline 0.2 & 1.244 & 1.643 & 0.028 & 0.024 & 0.331 & 1.245 & 1.409 & 0.022 & 0.019 & 0.301 \\
\hline 0.25 & 1.325 & 1.730 & 0.031 & 0.026 & 0.421 & 1.327 & 1.495 & 0.024 & 0.020 & 0.382 \\
\hline 0.3 & 1.417 & 1.827 & 0.035 & 0.027 & 0.515 & 1.420 & 1.591 & 0.027 & 0.021 & 0.466 \\
\hline 0.4 & 1.647 & 2.061 & 0.044 & 0.030 & 0.719 & 1.651 & 1.828 & 0.036 & 0.023 & 0.648 \\
\hline 0.5 & 1.966 & 2.367 & 0.060 & 0.034 & 0.956 & 1.973 & 2.149 & 0.048 & 0.027 & 0.857 \\
\hline 0.6 & 2.438 & 2.788 & 0.097 & 0.041 & 1.259 & 2.451 & 2.609 & 0.079 & 0.032 & 1.120 \\
\hline 0.7 & 3.203 & 3.423 & 0.224 & 0.056 & 1.746 & 3.228 & 3.237 & 0.195 & 0.045 & 1.544 \\
\hline 0.75 & 3.780 & 3.907 & 0.457 & 0.073 & 2.226 & 3.815 & 3,8 & 0.434 & 0.062 & 1.986 \\
\hline
\end{tabular}

Membrane material, cellulose acetate. Membrane specifications: $A=1.43 \times 10^{-6} \mathrm{~mol} \mathrm{H}_{2} 0 / \mathrm{cm}^{2}$ $\mathrm{s}$ atm, and $\left(\mathrm{D}_{\mathrm{AM}} / \mathrm{K} \delta\right)_{\mathrm{NaCl}}, 2.1 \times 10^{-5} \mathrm{~cm} / \mathrm{s}$. Feed solution, $0.4 \mathrm{molal} \mathrm{NaCl}-\mathrm{H}_{2} \mathrm{O}$. Operating pressure, 1000 psig. 


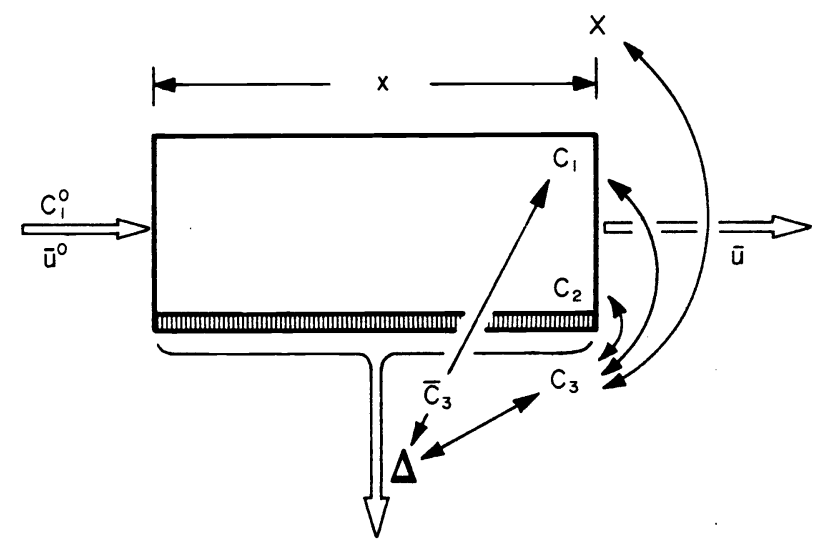

Fig. 2. Performance parameters for a reverse osmosis system

of the solution is constant, ( $i i)$ the osmotic pressure of the solution is proportional to the mole fraction of solute in the concentration range involved, ( $i i i)$ solute flux through the membrane is small compared to solvent flux, (iv) the solute transport parameter is independent of feed concentration and feed flow rate, and ( $v$ ) longitudinal diffusion of solute is regligible. For the purpose of system analysis, the dimensionless concentration $C$ is defined in terms of actual concentration ratios as

$C=X_{A} / X_{A I}^{\circ}$

so that $c_{1}=x_{A 1} / x_{A 1}^{0}, c_{1}^{0}=x_{A 1}^{0} / x_{A 1}^{0}=1, c_{2}=x_{A 2} / x_{A 1}^{0}, c_{2}^{0}=x_{A 2}^{0} / x_{A 1}^{0}, c_{3}=x_{A 3} / x_{A 1}^{0}$.

$c_{3}^{O}=X_{A 3}^{O} / X_{A 1}^{O}$ and $\bar{c}_{3}=\bar{X}_{A 3} / X_{A 1}^{O}$. Thus the quantities $c_{1}, c_{2}$, and $C_{3}$ represent the concentrations of the bulk solution and the concentrated boundary solution on the high pressure side of the membrane and the inembrane permeated product solution on the low pressure side of the membrane respectively at any point in the system; the quantities $C_{1}^{0}, C_{2}^{0}$, and $C_{3}^{O}$ are the values of $C_{1}, C_{2}$, and $C_{3}$ respectively at membrane entrance in flow process, or at start of operation in batch process; and, the quantity $\bar{C}_{3}$ is the average value of $c_{3}$ corresponding to a specified fraction $\Delta$ of product water recovery. Further, a dimensionless longitudinal length parameter $X$ for a flow process, and a dimensionless time parameter $\tau$ for a batch process are defined as:

$x=\frac{v_{w}^{*}}{u^{0}} \frac{x}{h}$

and $\tau=\frac{S v_{w}^{*} t}{v_{1}^{0}}$

When $(1 / h) \equiv\left(S / V_{1}^{\circ}\right)$, and $\left(x / u^{-0}\right) \equiv t$, the numerical values of $x$ and $\tau$ are identical.

The quantities $c_{1}, c_{2}, c_{3}, \bar{c}_{3}, \tau$ or $x$, and $\Delta$ represent the main performance data for any reverse osmosis system. Hence the precise relationships among them constitute a fundamental aspect of reverse osmosis transport.

On the basis of the transport Eqs. 13 to 16, and the foregoing assumptions and definitions, it has been shown (Ref. 1,85-87) that in any reverse osmosis system ( $F i g .2)$ specified in terms of $\gamma, \theta$, and $\lambda$, the quantities $v_{w}$ and $v_{w}^{*}, c_{2}$ and $c_{3}, c_{1}$ and $c_{3}, c_{1}$ and $\bar{c}_{3}, c_{3}$ and $\tau$ or $X$, and $C_{3}$ and $\Delta$ are uniquely related as follows:

$v_{w}=v_{w}^{*}\left[1-\gamma\left(c_{2}-C_{3}\right)\right]$

$c_{2}=c_{3}\left[1+\frac{1}{\left(\gamma c_{3}+\theta\right)}\right]$

$c_{2}^{0}=c_{3}^{0}\left[1+\frac{1}{\left(\gamma c_{3}^{0}+\theta\right)}\right]$

$c_{1}=c_{3}\left[1+\frac{1}{\left(\gamma c_{3}+\theta\right)^{\exp }}\left\{-\frac{1}{\lambda\left(\gamma c_{3}+\theta\right)}\right\}\right]$

$c_{1}^{0}=1=c_{3}^{0}\left[1+\frac{1}{\left(\gamma c_{3}^{0}+\theta\right)} \exp \quad\left\{-\frac{1}{\lambda\left(\gamma c_{3}+\theta\right)}\right\}\right]$ 
$c_{1}(1-\Delta)+\bar{c}_{3} \Delta=1$

$\Delta=1-\exp (-z)$

where $z=\int_{C_{3}^{0}}^{C_{3}}\left[\frac{\gamma}{\lambda\left(\gamma c_{3}+\theta\right)^{2}}-\frac{\gamma}{\left(\gamma C_{3}+\theta\right)}+\left\{\frac{\left(\gamma C_{3}+\theta\right)}{C_{3}} \exp \frac{1}{\lambda\left(\gamma C_{3}+\theta\right)}\right\}+\frac{1}{c_{3}}\right] d c_{3}$

and,

$\left(\begin{array}{l}\tau \\ o r \\ x\end{array}\right)=\int_{C_{3}}^{c_{3}}\left[\frac{\gamma}{\lambda\left(\gamma c_{3}+\theta\right)}-\gamma+\frac{\left(\gamma c_{3} \theta\right)}{C_{3}}\left\{1+\left(\gamma c_{3}+\theta\right) \exp \frac{1}{\lambda\left(\gamma c_{3}+\theta\right)}\right\}\right] \frac{\exp (-z)}{\theta} d c_{3}$

Equations 29 to 36 show that for a reverse osmosis system specified in terms of $\gamma, \theta$ and $\lambda$, any one of the six quantities $c_{1}, c_{2}, c_{3}, \bar{c}_{3}, \tau$ or $x$, and $\Delta$ uniquely fixes all the other five quantities. This is illustrated by the data given in Table 9 for the reverse osmosis treatment of a 0.4 molal $\mathrm{NaCl}-\mathrm{H}_{2} \mathrm{O}$ feed solution at $1000 \mathrm{psig}$ and different values of $\lambda \theta$, using a membrane specified in terms of $A$ and $\left(D_{A M} / K \delta\right)_{N a C l}$. Similar data for a large number of reverse osmosis systems are available in the form of a book of tables for ready use (Ref. 86). The application of system analysis in reverse osmosis process design has been illustrated in the literature (Ref. 81, 88-90).

\section{Expressions for $k, D_{A M} / K \delta$ and $f$ for very dilute feed solutions}

For such feed solutions, the molar density of the solution is essentially that of pure water, and the osmotic pressures involved during reverse osmosis are negligible compared to the usual operating pressures, which means that $(P R) \approx(P W P)$. Under these conditions, on the basis of the generalized mass transfer coefficient correlation (Ref. 78 ), $k$ for any solute can be obtained from the corresponding value of $k$ for a reference solute ( $k_{r e f}$ ) from the relation:

$k=k_{\text {ref }}\left[D_{A B} /\left(D_{A B}\right)_{\text {ref }}\right]^{2 / 3}$

where $D_{A B}$ and $\left(D_{A B}\right)$ ref are the diffusivities of the solute under consideration and the reference solute respectively in water. Further, applying the transport Eqs. 13 to 16 to

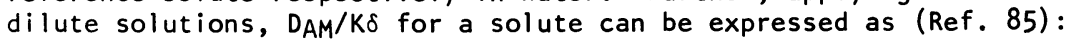

$D_{A M} / K \delta=\frac{(P R)}{3600 S \rho} \frac{(1-f)}{f}\left[\exp \left\{\frac{(P R)}{3600 \mathrm{~s} \rho \rho}\right\}\right]^{-1}$

and hence $f=\left[1+\frac{\left(D_{A M} / K \delta\right) 3600 \mathrm{~S} \rho}{(P R)} \exp \left\{\frac{(P R)}{3600 \mathrm{~S} \rho \rho}\right\}\right]^{-1}$

Let $v_{s}$ represent the permeation velocity $(\mathrm{cm} / \mathrm{s})$ of product solution expressed by

$\mathrm{v}_{\mathrm{s}}=\frac{(P R)}{3600 \mathrm{~s} \rho}$.

Equation 38 can then be written as

$D_{A M} / K \delta=v_{s}\left(\frac{1-f}{f}\right)\left[\exp \left(v_{s} / k\right)\right]^{-1}$

When $v_{s} / k$ is sufficiently small,

$\exp \left(v_{s} / k\right) \approx 1+\frac{v_{s}}{k}$

so that Eq. 41 can be written as

$f=\frac{v_{s}}{v_{s}\left(1+\frac{D_{A M} / K \delta}{k}\right)+D_{A M} / K \delta}$

When $D_{A M} / K \delta$ and $k$ are constants and $v_{S}$ is proportional to $P$, Eq. 43 becomes

$f=\frac{K^{\prime} P}{K^{\prime \prime} P+1}$ 
where $K^{\prime}$ and $K^{\prime \prime}$ are constants. Equation 44 has the same form as the familiar Langmuir adsorption equation which of course should be expected on the basis of the preferential sorption-capillary flow mechanism for reverse osmosis.

Equations 43 and 44 are subject to the restrictions (a) $D_{A M} / K \delta$ is a constant, (b) $k$ is a constant, (c) $v_{s} \propto P$, and (d) $v_{s} / k$ is sufficiently small; under these restrictions, $f$ tends to increase with increase in $P$. If however, the restriction (d) above is removed, then the solute separation $f$ may be expected to pass through a maximum at $v_{s} / k=1$ with increase in operating pressure (Ref. 85 ). This conclusion is significant from the point of view of the engineering science of reverse osmosis transport.

\section{Relationships between $\left(D_{A M} / K \delta\right)$ NaCl and $D_{A M} / K \delta$ for other solutes}

Correlating experimental reverse osmosis data for suitably chosen nonionized polar organic solutes with Taft's polar $\left(\Sigma \sigma^{*}\right)$ and steric $\left(\Sigma E_{s}\right)$ parameters on the basis of the form of Hammett and Taft equations (Ref. 36), it was found that $D_{A M} / K \delta$ for the solute was directly proportional to the exponential sum of the polar and steric effects expressed by the quantities $\rho * \Sigma \sigma *$ and $\delta * \Sigma E_{S}$ respectively (Ref. 38 ). Extending the basis of the above correlations to include the nonpolar effect, and using $\Sigma(-\Delta \Delta G / R T)$ to express the polar effect instead of $\rho \star \Sigma \sigma *$, the most general expression for $D_{A M} / K \delta$ for a nonionized polar organic solute can be given by the relation:

$D_{A M} / K \delta \propto \exp \left[\Sigma(-\Delta \Delta G / R T)+\delta \star \Sigma E_{S}+\omega \star \Sigma s \star\right]$

The coefficients $\rho *, \delta *$, and $\omega *$ associated with the parameters $\Sigma \sigma^{*}, \Sigma E_{\mathrm{S}}$, and $\Sigma s^{*}$ respectively, are characteristic of the membrane-solution interface, i.e., chemical nature of the membrane material, solvent, and functional group in the solute molecule; in addition, the values of $\delta^{*}$ depend on the porous structure of the membrane surface. With respect to completely ionized inorganic and simple organic solutes, it was found (Ref. 30, 32) that

$D_{A M} / K \delta \propto \exp \Sigma\left(-\frac{\Delta \Delta G}{R T}\right)$ ion

This means that the steric and nonpolar effects included in Eq. 45 can be neglected for such solutes; this simplification may not however be valid for completely ionized molecules of complex molecular structure.

On the basis of Eqs. 45 and 46, the following relationships have been established (Ref. 30-34) for obtaining the values of $D_{A M} / K \delta$ for different solutes from data on $D_{A M} / K \delta$ for $N a C l$ only. From Eq. 46,

$\ln \left(D_{A M} / K \delta\right)_{\mathrm{NaCl}}=\ln C_{\mathrm{NaCl}}^{*}+\sum\left[\left(-\frac{\Delta \Delta G}{R T}\right)_{\mathrm{Na}^{+}}+\left(-\frac{\Delta \Delta G}{R T}\right)_{\mathrm{Cl}^{-}}\right]$

where $\ln \mathrm{C}_{\mathrm{NaCl}}^{*}$ is a constarit representing the porous structure of the membrane surface. This value of $\ln \mathrm{C}_{\mathrm{NaCl}}^{+}$is used in the following equations.

Completely ionized inorganic solutes.

$$
\begin{aligned}
\ln \left(D_{A M} / K \delta\right)_{\text {solute }} & =\ln C_{N a C l}^{*}+\sum n_{\text {ion }}\left(-\frac{\Delta \Delta G}{R T}\right) \text { ion } \\
= & \ln C_{\mathrm{NaCl}}^{*}+\left\{n_{c}\left(-\frac{\Delta \Delta G}{R T}\right)_{\text {cation }}+n_{a}\left(-\frac{\Delta \Delta G}{R T}\right)_{\text {anion }}\right\}
\end{aligned}
$$

where $n_{c}$ and $n_{a}$ represent the number of moles of cations and anions respectively in one mole of ionized solute. The free energy. parameter for various ions for use in Eqs. 47 and 49 are given in Table 1 for cellulose acetate membranes.

Nonionized polar organic solutes.

$\ln \left(D_{A M} / K \delta\right)_{\text {solute }}=\ln C_{N a C l}+\ln \Delta *+\left(-\frac{\Delta \Delta G}{R T}\right)+\delta * \Sigma E_{S}+\omega * \Sigma s *$

Referring to the quantities on the right side of Eq. 50, the quantity In $\mathrm{C}_{\mathrm{NaCl}}^{*}$ arises from Eq. 47. From data on $\left(D_{A M} / K \delta\right)_{\mathrm{NaCl}}$, the value of $\mathrm{ln} \mathrm{C}_{\mathrm{NaCl}}^{*}$ can be calculated for any membrane using the values of $-\Delta \Delta G / \mathrm{RT}$ for $\mathrm{Na}^{+}$and $\mathrm{Cl}^{-}$ions appropriate for the membrane material used as given in Table 6 .

The quantity $\ln \Delta^{*}$ sets a scale for $\ln \left(D_{A M} / K \delta\right)$ for the solute in terms of $\ln C_{N a C l}$ when the parameters representing the polar, steric, and nonpolar effects at the membrane-solution interface are each set equal to zero. Thus In $\Delta^{*}$ is simply a scale factor, and it is a function of the chemical nature of the membrane material and the porous structure of the 
membrane surface. Representing the former by the $\beta$-parameter discussed earlier, and the latter by the quantity in $\left(\mathrm{C}_{\mathrm{NaCl}}^{*} / \mathrm{A}\right)$, correlations of $\beta$ versus in $\Delta^{*}$ for various values of $\ln \left(C_{\mathrm{NaCl}}^{*} / \mathrm{A}\right)$ have been established from experimental reverse osmosis data (Ref. 47), arbitrarily setting in $\Delta^{*}=0$ for all membrane materials when the average pore size on the membrane surface is sufficiently small $\left(\ln \left(C_{\text {NaCl }}^{*} / A\right) \leqq 2\right)$. These correlations are given in Fig. 3. It has been found that these correlations are valid for all classes of nonionized
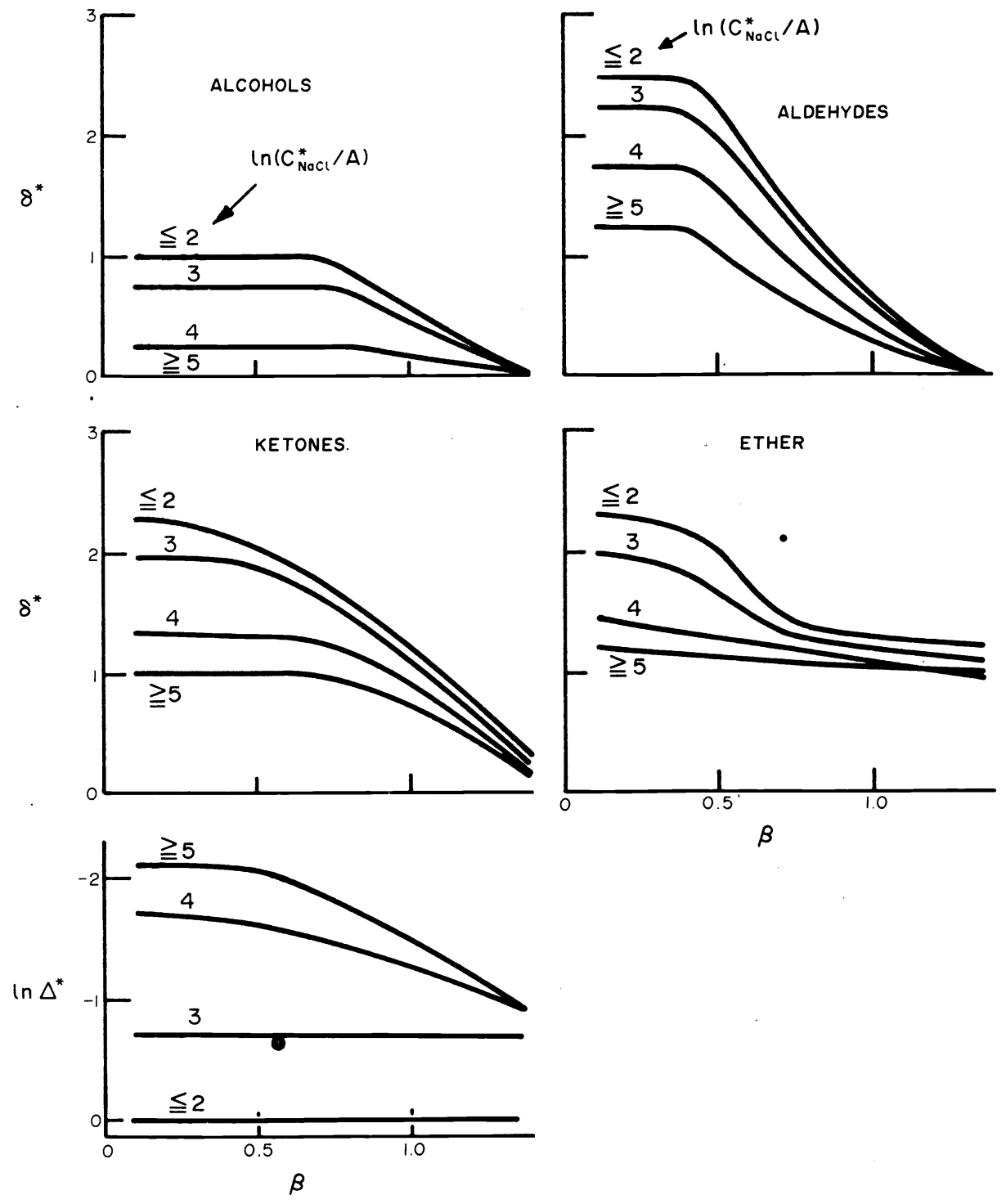

\section{$\beta$}

Fig. 3. Correlations of $\beta$-parameter for the polymer material versus $\delta *$ (applicable for alcohol-, aldehyde-, ketone-, and ether-solutes) and. In $\Delta^{*}$ (applicable for all organic solutes) as functions of $\ln \left(\mathrm{C}_{\mathrm{NaCl}}^{*} / \mathrm{A}\right)(\operatorname{Ref} .47)$.

polar organic solutes, and they are independent of the operating pressure in reverse osmosis. The reason for using $\ln \left(\mathrm{C}_{\mathrm{NaCl}}^{*} / \mathrm{A}\right)$ instead of $\ln \mathrm{C}_{\mathrm{NaCl}}^{*}$ in the above correlations is this: the numerical value of $\mathrm{C}_{\mathrm{NaCl}}^{*}$ is directly proportional to that of $A$, and hence the quantity $\mathrm{C}_{\mathrm{NaCl}}^{*} / \mathrm{A}$ offers a unified scale for expressing widely varying surface porosities resulting from different methods of film casting.

The quantity $-\Delta \Delta G / R T$ for different organic solute molecules can be obtained by using Eqs. 2 to 4 . The required data on structural group contributions are given in Table 2 for cellulose acetate material, and in Tables 5 and 6 for other membrane materials characterized by their $\beta$-parameters; these data are applicable to both monofunctional and polyfunctional solute molecules. 
The quantity $\delta *$ is a function of the chemical nature of the solute molecule, membrane material, and porous structure of the membrane surface; the steric parameter $\Sigma E_{S}$ for the substituent group in the solute molecule can be obtained from Taft's table in Ref. 36 . The latter values of $\sum E_{S}$ are however applicable only for solute molecules involving monofunctional groups. For such solute molecules, the correlations of $\beta$ versus $\delta *$ for various values of $\ln \left(\mathrm{C}_{\mathrm{NaCl}} / \mathrm{A}\right)$ have been established from experimental reverse osmosis data (Ref. 47) as given in Fig. 3. The data show that $\delta *=0$ for alcohol- and aldehyde-solutes for all cellulose acetate membranes. It must be noted that the $\delta *$ values obtained from Fig. 3 are valid only for the class of solutes indicated therein; further, they are not applicable for solute molecules involving polyfunctional groups. Practical techniques have however been established for estimating the quantity $\delta * \Sigma E_{S}$ for solute molecules involving polyfunctional groups with respect to cellulose acetate membrane material (Ref. 31). Again these correlations of $\delta *$ and $\delta * \sum E_{S}$ have been found to be independent of operating pressure in reverse osmosis.

The quantity $\omega *$ is a function of the chemical nature of the solute and the membrane material, and independent of the porous structure of the membrane surface. The value of $\Sigma s *$ for the substituent group in the organic solute molecule can be obtained from the data on structural group contributions given in Table 3. The value of w* will then depend upon the chemical nature of the functional group in the solute molecule and on the chemical nature of the membrane material. For $C_{1}$ to $C_{9}$ monohydric alcohol-solutes and cellulose acetate membrane material, the values of $\omega^{*}$ have been experimentally determined to be as follows (Ref. 91):

\begin{tabular}{|c|c|c|}
\hline$\Delta S *$ (alcohol) & $n_{c}$ & $\mathrm{cal}^{-\frac{1}{2}} \mathrm{~cm} \times 10^{3}-\frac{3}{2} \mathrm{~mol}$ \\
\hline $\begin{array}{r}0 \\
-24 \\
-48 \\
0 \\
-24 \\
-64,-72 \\
-88\end{array}$ & $\begin{array}{l}1 \text { to } 3 \\
3 \text { to } 5 \\
6 \text { and } 7 \\
4 \text { to } 8 \\
6 \text { to } 9 \\
4 \text { to } 7 \\
6 \text { and } 7\end{array}$ & $\begin{array}{c}0 \\
0 \\
0 \\
2.1 \\
1.2 \\
-1.0 \\
-2.2\end{array}$ \\
\hline
\end{tabular}

where $\mathrm{n}_{\mathrm{c}}=$ number of carbon atoms in the alcohol molecule, and

$\Delta s *($ alcohol $)=\Sigma s *($ alcohol $)-\Sigma s *($ straight chain primary alcohol with the same number of carbon atoms)

For example, $\triangle \mathrm{s} *\left(\mathrm{CH}_{3} \mathrm{CHOHCH}_{3}\right)=\Sigma \mathrm{s} *\left(\mathrm{CH}_{3} \mathrm{CHOHCH}_{3}\right)-\Sigma \mathrm{s} *\left(\mathrm{CH}_{3} \mathrm{CH}_{2} \mathrm{CH}_{2} \mathrm{OH}\right)$ $=456-480=-24$.

As the degree of branching increases, the value of $\Delta s *$ becomes more negative. An increase in the value of $\omega^{*}$ denotes greater nonpolar attraction of the solute towards the membrane surface whereas a decrease $\omega *$ denotes lesser such attraction.

With respect to all solute molecules containing no more than three straight chain carbon atoms not associated with a polar functional group, the quantity $\omega * \Sigma s *$ may be assumed to be zero for cellulose acetate membranes for purposes of computing ln ( $D_{A M} / K \delta$ ) solute values from $E q .50$ by the method outlined above. Further, experimental data with $\mathrm{Cl}_{1}$ - $\mathrm{C}_{9}$ alcohol-solutes and cellulose acetate membranes show that, at the membrane-solution interface, the change from preferential sorption of water to that of solute occurs at the $\omega * \Sigma s *$ value of about 2.5 .

Illustrative results. For a given membrane, a single set of reverse osmosis experiments with a reference feed solution $\mathrm{NaCl}-\mathrm{H}_{2} \mathrm{O}$ at a chosen operating pressure and temperature, yields values of $A,\left(D_{A M} / K \delta\right)_{\mathrm{NaCl}}$ and $k_{\mathrm{NaCl}}$. From the above value of $\left(D_{A M} / K \delta\right)_{\mathrm{NaCl}}$, the value of $D_{A M} / K \delta$ for any other solute can be calculated from Eqs. 49 and 50 . Using the basic transport Eqs. 13 to 16 , one can then predict the performance of the membrane (solute separation and product rate) with respect to any other solute for any specified value of $k$. This is illustrated in Tables 10 and 11 with particular reference to very dilute solutions for which case $(P R) \approx(P W P)$, and Eqs. 37 and 39 are applicable. Using these equations, for a cellulose acetate $(\beta=1.37)$ membrane specified in terms of $A=1.43 \times 10^{-6} \mathrm{~mol} \mathrm{H} 20 / \mathrm{cm}^{2} \mathrm{~s}$ atm, and $\left(D_{A M} / K \delta\right)_{\mathrm{NaCl}}=2.10 \times 10^{-5} \mathrm{~cm} / \mathrm{s}$ at $250 \mathrm{psig}$, the obtainable solute separations for a number of completely ionized inorganic solutes and nonionized polar organic solutes in single solute systems at $k$ values corresponding to $\mathrm{kNaCl}=22 \times 10^{-4} \mathrm{~cm} / \mathrm{s}$ were calculated, and the results are given in Table 10. For membranes of the same specification and for the same values of $k$, the obtainable levels of solute separation for a number of organic solutes with different membrane materials were calculated and the results are given in Table 11 as a function of the $\beta$-parameter. These results illustrate the practical utility of both the transport equations and the related correlations, and the concepts of specification of membranes and membrane materials. 
TABLE 10. Reverse osmosis separations for some inorganic and organic solutes in single-solute dilute aqueous solutions for a cellulose acetate membrane predicted from data on $A,\left(D_{A M} / K \delta\right)_{\mathrm{NaCl}}$ and $k_{\mathrm{NaCl}}$

$$
\begin{aligned}
A= & 1.43 \times 10^{-6} \mathrm{~mol} \mathrm{H}_{2} 0 / \mathrm{cm}^{2} \mathrm{~s} \text { atm, }\left(D_{\mathrm{AM}} / \mathrm{K} \delta\right)_{\mathrm{NaCl}}=2.10 \times 10^{-5} \mathrm{~cm} / \mathrm{s}, \\
& \text { and } \mathrm{k}_{\mathrm{NaCl}}=22 \times 10^{-4} \mathrm{~cm} / \mathrm{s} \text { at operating pressure }=250 \mathrm{psig}
\end{aligned}
$$

\begin{tabular}{|c|c|c|c|c|c|}
\hline Solute & $\begin{array}{c}\mathrm{k} \times 10^{4} \\
\mathrm{~cm} / \mathrm{s}\end{array}$ & $\begin{array}{r}\text { Solute } \\
\text { sepn, \% }\end{array}$ & Solute & $\begin{array}{l}\mathrm{k} \times 10^{4} \\
\mathrm{~cm} / \mathrm{s}\end{array}$ & $\begin{array}{r}\text { Solute } \\
\text { sepn, \% }\end{array}$ \\
\hline $\begin{array}{l}\text { lonized inorganic } \\
\text { Aluminum nitrate } \\
\text { Ammonium chloride } \\
\text { Ammonium nitrate } \\
\text { Barium chloride } \\
\text { Barium nitrate } \\
\text { Cadmium nitrate } \\
\text { Calcium chloride } \\
\text { Calcium nitrate } \\
\text { Cobalt nitrate } \\
\text { Copper nitrate } \\
\text { Ferric nitrate } \\
\text { Ferrous chloride } \\
\text { Lead nitrate } \\
\text { Lithium chloride } \\
\text { Lithium nitrate } \\
\text { Magnesium chloride } \\
\text { Magnesium nitrate } \\
\text { Manganous nitrate } \\
\text { Nickel nitrate } \\
\text { Potassium chloride } \\
\text { Potassium nitrate } \\
\text { Sodium bicarbonate } \\
\text { Sodium bromide } \\
\text { Sodium carbonate } \\
\text { Sodium chloride } \\
\text { Sodium fluoride } \\
\text { Sodium nitrate } \\
\text { Sodium nitrite } \\
\text { Sodium sulfite } \\
\text { Sodium sulfate } \\
\text { Sodium thiosulfate } \\
\text { Strontium chloride } \\
\text { Strontium nitrate } \\
\text { Thorium nitrate } \\
\text { Zinc nitrate }\end{array}$ & $\begin{array}{l}16.0 \\
25.3 \\
24.8 \\
20.0 \\
19.5 \\
18.9 \\
19.4 \\
18.9 \\
18.5 \\
18.3 \\
16.9 \\
18.6 \\
20.1 \\
19.7 \\
19.4 \\
18.6 \\
18.2 \\
18.3 \\
18.3 \\
25.3 \\
24.7 \\
18.6 \\
22.1 \\
17.7 \\
22.0 \\
20.1 \\
21.6 \\
20.4 \\
18.3 \\
18.4 \\
18.8 \\
19.6 \\
19.0 \\
12.2 \\
18.2\end{array}$ & $\begin{array}{l}99.1 \\
93.6 \\
87.2 \\
98.9 \\
95.2 \\
94.2 \\
98.4 \\
93.2 \\
94.0 \\
95.6 \\
99.5 \\
97.6 \\
95.7 \\
94.5 \\
88.8 \\
98.7 \\
94.1 \\
94.8 \\
95.4 \\
94.0 \\
87.9 \\
97.6 \\
93.5 \\
99.7 \\
94.5 \\
96.5 \\
88.9 \\
90.5 \\
99.7 \\
99.7 \\
99.9 \\
98.1 \\
93.9 \\
99.8 \\
93.9\end{array}$ & $\begin{array}{l}\text { Nonionized organic } \\
\text { Methyl alcohol } \\
\text { Ethyl alcohol } \\
\text { n-Propyl alcohol } \\
\text { i-Propyl alcohol } \\
\text { n-Butyl alcohol } \\
\text { s-Butyl alcohol } \\
\text { i-Butyl alcohol } \\
\text { t-Butyl alcohol } \\
\text { Acetaldehyde } \\
\text { Propionaldehyde } \\
\text { n-Butyraldehyde } \\
\text { i-Butyraldehyde } \\
\text { Acetone } \\
\text { Methyl ethyl ketone } \\
\text { Methyl propyl ketone } \\
\text { Methyl i-propyl ketone } \\
\text { Methyl propyl ether } \\
\text { Methyl i-propyl ether } \\
\text { Ethyl i-propyl ether } \\
\text { Ethyl t-butyl ether } \\
\text { Ethylene glycol } \\
\text { Trimethylene glycol } \\
\text { Propylene glycol } \\
\text { Glycerol } \\
\text { Arabitol } \\
\text { Xylitol } \\
\text { D-Sorbitol } \\
\text { Dulcitol } \\
\text { D-Glucose } \\
\text { D-Mannose } \\
\text { D-Galactose } \\
\text { D-Fructose } \\
\text { Sucrose } \\
\text { Maltose } \\
\text { Lactose }\end{array}$ & $\begin{array}{l}24.9 \\
20.6 \\
18.2 \\
18.2 \\
16.5 \\
16.5 \\
16.5 \\
16.5 \\
21.5 \\
18.7 \\
16.8 \\
16.8 \\
18.7 \\
16.8 \\
15.4 \\
15.4 \\
16.4 \\
16.4 \\
15.1 \\
14.0 \\
19.7 \\
17.5 \\
17.6 \\
17.0 \\
14.0 \\
14.0 \\
13.1 \\
13.1 \\
13.3 \\
13.3 \\
13.3 \\
13.3 \\
9.9 \\
9.9 \\
9.9\end{array}$ & $\begin{array}{l}5.4 \\
11.3 \\
19.9 \\
35.2 \\
14.4 \\
37.4 \\
37.4 \\
79.8 \\
31.1 \\
33.1 \\
35.4 \\
34.5 \\
18.3 \\
20.1 \\
22.2 \\
34.4 \\
31.3 \\
43.8 \\
49.0 \\
86.4 \\
52.9 \\
55.9 \\
60.8 \\
77.9 \\
97.5 \\
97.5 \\
99.2 \\
99.2 \\
99.0 \\
99.0 \\
99.0 \\
99.0 \\
99.8 \\
99.8 \\
99.8\end{array}$ \\
\hline
\end{tabular}

TABLE 11. Effect of membrane material ( $\beta$-parameter) on reverse osmosis

\begin{tabular}{|c|c|c|c|c|c|c|c|c|}
\hline \multirow{3}{*}{ Solute } & \multicolumn{8}{|c|}{$\beta$-parameter } \\
\hline & 0.17 & 0.20 & 0.46 & 0.67 & 0.74 & 1.16 & 1.26 & 1.37 \\
\hline & \multicolumn{8}{|c|}{ Solute separation, $\%$} \\
\hline $\begin{array}{l}\text { n-Propyl alcohol } \\
\text { i-Propyl alcohol } \\
\text { t-Butyl al cohol } \\
\text { Propionaldehyde } \\
\text { i-Butyraldehyde } \\
\text { Methyl ehtyl ketone } \\
\text { Diisopropyl ketone } \\
\text { Methyl isopropyl ketone } \\
\text { Butyl ethyl ether } \\
\text { t-Butyl ethyl ether }\end{array}$ & $\begin{array}{l}67.4 \\
69.4 \\
94.6 \\
59.7 \\
87.4 \\
68.3 \\
97.5 \\
87.4 \\
84.6 \\
97.9\end{array}$ & $\begin{array}{l}67.4 \\
69.6 \\
94.6 \\
60.5 \\
87.7 \\
63.4 \\
94.5 \\
87.2 \\
85.9 \\
98.1\end{array}$ & $\begin{array}{l}67.4 \\
71.5 \\
95.2 \\
60.5 \\
86.0 \\
57.6 \\
95.9 \\
82.7 \\
83.3 \\
98.2\end{array}$ & $\begin{array}{l}60.3 \\
66.6 \\
94.0 \\
53.1 \\
75.0 \\
49.7 \\
92.5 \\
74.9 \\
84.8 \\
96.4\end{array}$ & $\begin{array}{l}57.4 \\
64.5 \\
93.0 \\
48.6 \\
61.7 \\
45.7 \\
90.2 \\
70.4 \\
82.4 \\
95.3\end{array}$ & $\begin{array}{l}37.7 \\
36.8 \\
74.2 \\
29.6 \\
34.9 \\
19.9 \\
49.0 \\
30.3 \\
50.2 \\
81.7\end{array}$ & $\begin{array}{l}22.8 \\
28.9 \\
56.5 \\
25.1 \\
27.5 \\
16.0 \\
35.6 \\
22.5 \\
37.9 \\
73.4\end{array}$ & $\begin{array}{l}19.9 \\
35.2 \\
79.8 \\
33.1 \\
34.5 \\
20.1 \\
38.4 \\
34.4 \\
40.0 \\
86.4\end{array}$ \\
\hline
\end{tabular}
separations of some organic solutes in dilute aqueous solutions

Membrane specifications: $A=1.43 \times 10^{-6} \mathrm{~mol} / \mathrm{cm}^{2} \mathrm{~s}$ atm, and $\left(D_{A M} / \mathrm{K \delta}\right)_{\mathrm{NaCl}}=2.10 \times 10^{-5} \mathrm{~cm} / \mathrm{s}$. Operating pressure, $250 \mathrm{psig}$. Feed flow rate corresponding to $\mathrm{k}_{\mathrm{NaCl}}=22 \times 10^{-4} \mathrm{~cm} / \mathrm{s}$. 
Practically all natural and industrial solutions amenable for reverse osmosis treatment are mixed solute systems, and hence they need extensive study and analysis. Even though such study and analysis involve many computational complexities and problems which have not yet been explored in detail, the basic validity of the transport equations discussed above for the mixed solute systems in general has been established (Ref. 32-34, 37, 92-95). A few simple cases of the application of the basic transport equations for mixed solute systems may be cited here as follows.

For the case of an inorganic solute which is partially hydrolyzed, Eq. 48 becomes (Ref. 34 ):

$$
\begin{aligned}
\ln (D A M / K \delta)_{\text {solute }} & =\ln C_{\text {NaCl }}^{*}+\left(1-\alpha_{H}\right)\left[n_{c}\left(-\frac{\Delta \Delta G}{R T}\right)_{\text {cation }}+n_{a}\left(-\frac{\Delta \Delta G}{R T}\right)_{\text {anion }}\right] \\
& +\alpha_{H}\left[n_{h y}\left(-\frac{\Delta \Delta G}{R T}\right)_{h y}+\left(-\frac{\Delta \Delta G}{R T}\right)_{\mathrm{OH}^{-}} \text {or } H^{+}\right]
\end{aligned}
$$

where $\alpha_{H}$ represents degree of hydrolysis, and the subscripts hy and $\mathrm{OH}^{-}$or $\mathrm{H}^{+}$refer to the hydrolyzed species resulting from the hydrolysis reaction and hydroxyl or hydrogen ions respectively.

For the case of an aqueous solution of an inorganic solute where both dissociation and ionpair formation occur, Eq. 48 becomes (Ref. 34)

$$
\begin{aligned}
\ln \left(D_{A M} / K \delta\right) \text { solute } & =\ln C_{\text {NaCl }}^{*}+\alpha_{D}\left[n_{c}\left(-\frac{\Delta \Delta G}{R T}\right)_{c a t i o n}+n_{a}\left(-\frac{\Delta \Delta G}{R T}\right)_{\text {anion }}\right] \\
& +\left(1-\alpha_{D}\right)\left(-\frac{\Delta \Delta G}{R T}\right)_{i p} \\
& +\left(1-\alpha_{D}\right)\left(n_{c}-n_{i p c}\right)\left(-\frac{\Delta \Delta G}{R T}\right)_{c a t i o n} \\
& +\left(1-\alpha_{D}\right)\left(n_{a}-n_{i p a}\right)\left(-\frac{\Delta \Delta G}{R T}\right)_{\text {anion }}
\end{aligned}
$$

Where $\alpha_{D}$ represents degree of dissociation, the subscript ip refers to the ion-pair formed, and $n_{i p c}$ and $n_{i p a}$ are number of moles of cations and anions respectively in one mole of ionpair.

When an organic solute is partially dissociated, the flux of total solute through the membrane is simply the sum of the flux of ionized solute and that of nonionized solute through the membrane. The latter two quantities can be separately estimated from ( $D_{A M} / K \delta$ ) for the ionized solute and that for the nonionized solute obtained from Eqs. 48 and 50 (Ref. 32). The same additivity principle applies for a mixture of nonionized solutes (Ref. 37,94$)$, or a mixture of ionized solutes with a common ion (Ref. 92, 93).

When a solution contains a number of completely ionized solutes with no common ion, then the basic transport Eqs. 13 to 16 have to be rewritten for each ion along with relevant equations for total electroneutrality in the system. A full analysis of such a system of equations has recently been carried out in detail for aqueous feed solutions containing two uni-univalent electrolytic solutes with or without a common ion (Ref. 95).

\section{APPLICATIONS}

The above discussions on transport are particularly relevant for the reverse osmosis treatment of aqueous solutions where water is preferentially sorbed at the membrane-solution interface. This case includes a vast area of water treatment applications such as water desalination, water pollution control, water reuse, water purification, and waste recovery; a special case of such treatment of aqueous solutions is the application of reverse osmosis in food processing for which the foregoing discussions on transport offer a fundamental approach (Ref. 96-100). The other case of water treatment applications where solute is preferentially sorbed at the membrane-solution interface, is equally important and is yet to be explored in detail. Further, reverse osmosis is not limited to the treatment of aqueous solutions. The applicability of reverse osmosis for the treatment of nonaqueous solutions (Ref. 87, 101-103), and gaseous mixtures (Ref. 104-107) has been demonstrated. These applications, along with those mentioned above, unfold a new area of chemical process engineering of enormous potential significance. The practical success of every application depends on the nature and magnitude of forces prevailing at the membrane-solution interface, choice of membrane material, development of membranes of appropriate porous structure, and the laws governing transport through reverse osmosis membranes, all of which from part of the 
science of reverse osmosis. Consequently, all applications of reverse osmosis arise from the science of reverse osmosis (Ref. 108).

\section{CONCLUSION}

Reverse osmosis is a science - a new and useful one. The physicochemical basis for reverse osmosis separations, the materials science of reverse osmosis membranes, and the engineering science of reverse osmosis transport are the major components of this science. All applications of reverse osmosis arise from this science which is still in its very early stages of development. Renewed and dedicated efforts are called for to unfold this science in all its aspects. The obvious potential of reverse osmosis to contribute significantly to the health and prosperity of all humanity makes such efforts profoundly relevant, meaningful and worthwhile.

Acknowledgment - The author thanks Dr. Takeshi Matsuura for his help in preparing this paper.

\section{NOMENCLATURE}

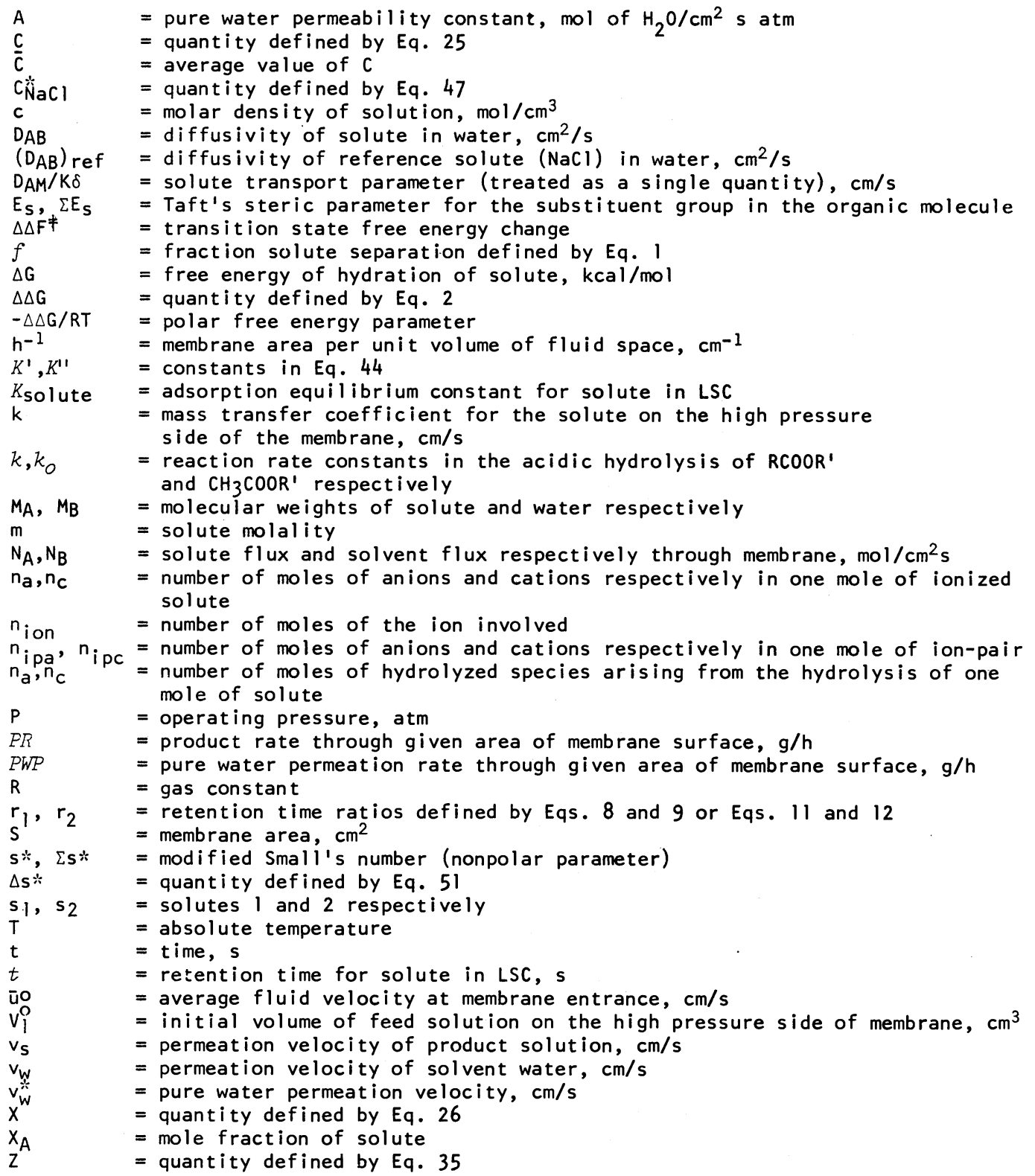




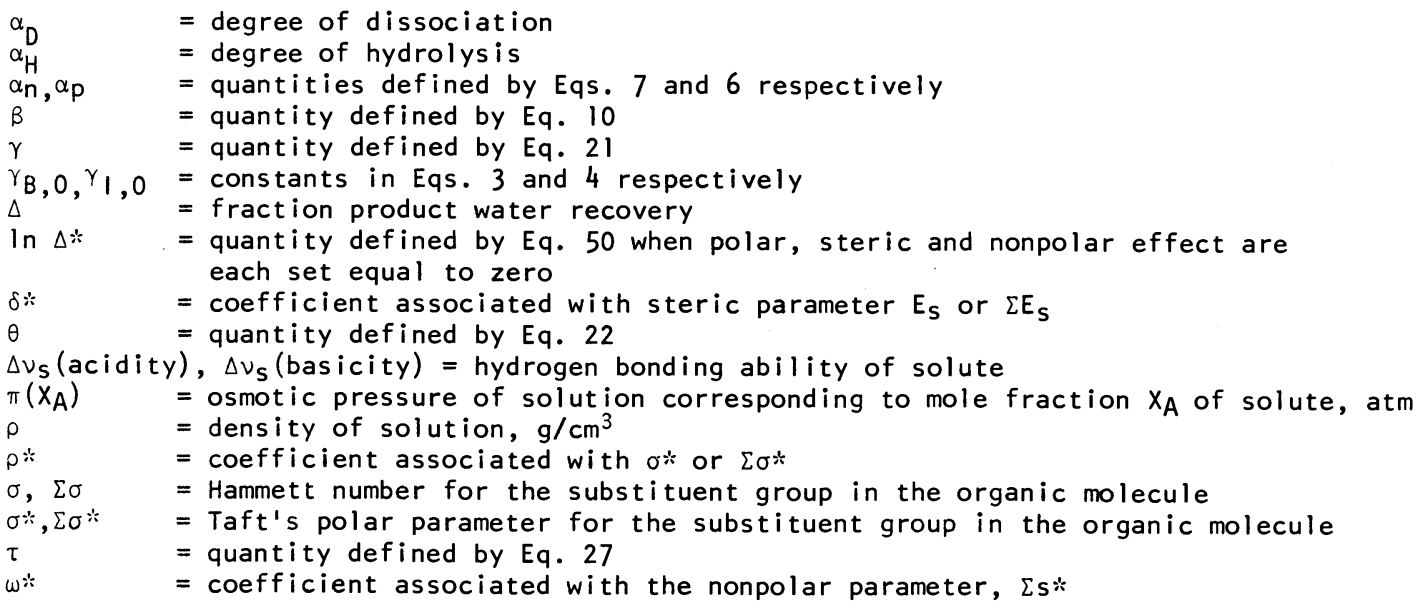

Subscripts

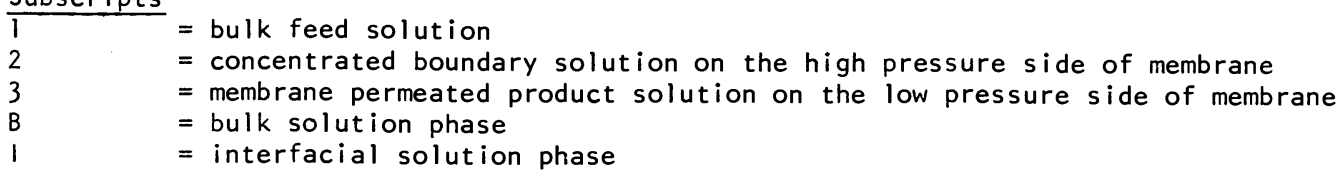

Superscript

- $\quad$ initial value, or value at membrane entrance

\section{REFERENCES}

1. S. Sourirajan, Reverse Osmosis, Academic, New York (1970).

2. S. Sourirajan, in Reverse Osmosis and Synthetic Membranes, Chap. 1, S. Sourirajan, Ed., National Research Council Canada, Ottawa (1977).

3. E.J. Breton, Jr., RED Progress Report No. 16, OSW, U.S. Dept. Interior, Washington, D.C. (1957).

4. E. Glueckauf, Proc. First Intern. Symp. on Water Desalination, Washington, D.C., 1965, 1, 143-156.

5. H.K. Lonsdale, U. Merten and R.L. Riley, J. Appl. Polym. Sci. 9, 1341-1362 (1965).

6. A.L. Vincent, M.K. Barsh and R.E. Kesting, J. Appl. Polym. Sci - 9 , 2363-2378 (1965).

7. C.P. Bean, RED Progress Report No. 465, OSW, U.S. Dept. Interior, Washington, D.C. (1969).

8. B.M. Misra and J.W. McCutchan, Report No. UCLA-ENG-7137, University of California, Los Angeles (1971).

9. C. Kamizawa and J.W. McCutchan, Report No. UCLA-ENG-7158, University of California, Los Angeles (1971).

10. J.E. Anderson, S.J. Hoffman and C.R. Peters, J. Phys. Chem. 76, 4006-4011 (1972).

11. Yu. N. Dytnerskii, G.V. Polyakov and L.S. Lukavyi, Theor. Found. Chem. Eng. 6, 565-568 (1972).

12. K.W. Choi and D.N. Bennion, Report No. UCLA-ENG-7370, University of California, Los Angeles (1973).

13. M.E. Heyde, C.R. Peters and J.E. Anderson, J. Coll. Interface Sci. 50, 467-487 (1975).

14. H.H.P. Fang and E.S.K. Chian, J. Appl. Polym. Sci. 19, 2889-2895 (1975).

15. H.K. Johnston, Desalination 16, 205-224 (1975).

16. L. Dresner and J.S. Johnson, Jr., in Principles of Desalination, 2nd ed., K.S. Spiegler and A.D.K. Laird, Eds., Academic, New York (in press).

17. University of California, Office of Public Information, Press Release, New Water Desalting Process Developed at UCLA, Aug. 23, 1960.

18. S. Loeb and S. Sourirajan, Report No. 60-60, Dept. Engineering, University of California, Los Angeles (1961).

19. S. Loeb and S. Sourirajan, Advan. Chem. Ser. No. 38, 117-132 (1963).

20. S.T. Yuster, S. Sourirajan and K. Bernstein, Report No. 58-26, Dept. Engineering, University of California, Los Angeles (1958).

21. S. Sourirajan, Ind. Eng. Chem. Fundamentals 2, $51-55$ (1963).

22. S. Sourirajan and T. Matsuura, in Reverse Osmosis and Synthetic Membranes, Chap. 2, S. Sourirajan, Ed., National Research Council Canada, Ottawa (1977).

23. T. Matsuura and S. Sourirajan, J. Appl. Polym. Sci. 15, 2905-2927 (1971).

24. T. Matsuura and S. Sourirajan, J.Appl. Polym. Sci. $\frac{16}{16}, 1663-1686$ (1972).

25. T. Matsuura and S. Sourirajan, J.Appl. Polym. Sci. 16, 2531-2554 (1972). 
26. T. Matsuura and S. Sourirajan, J. Appl. Polym. Sci. 17, 1043-1071 (1973).

27. T. Matsuura and S. Sourirajan, J.Appl. Polym. Sci. $17,3661-3682$ (1973).

28. T. Matsuura and S. Sourirajan, J.Appl. Polym. Sci. $17,3683-3708$ (1973).

29. T. Matsuura and S. Sourirajan, J.Appl. Polym. Sci. $18,3593-3620$ (1974).

30. T. Matsuura, L. Pageau and S. Sourirajan, J.Appl. Polym. Sci. 19, 179-198 (1975).

31. T. Matsuura, J.M. Dickson and S. Sourirajan, Ind. Eng. Chem. Process Des. Dev. 15, 149-161 (1976).

32. T. Matsuura, J.M. Dickson and S. Sourirajan, Ind. Eng. Chem. Process Des. Dev. 15, 350-357 (1976).

33. R. Rangarajan, T. Matsuura, E.C. Goodhue and S. Sourirajan, Ind. Eng. Chem. Process Des. Dev. 15, 529-534 (1976).

34. R. Rangarajan, T. Matsuura, E.C. Goodhue and S. Sourirajan, Free Energy Parameters for Reverse Osmosis Separations of Some Inorganic lons and Ion-pairs in Aqueous Solutions - Part 11, Ind. Eng. Chem. Process Des. Dev. (submitted) (1977).

35. J.0'M. Bockris and A.K.N. Reddy, Modern Electrochemistry, Vol. 1, Chap. 2, Plenum, New York (1970).

36. R.W. Taft, Jr., in Steric Effects in Organic Chemistry, M.S. Newman, Ed., 556-675, Wiley, New York (1956).

37. T. Matsuura, M.E. Bednas and S. Sourirajan, J. Appl. Polym. Sci. 18, 567-588 (1974).

38. T. Matsuura, M.E. Bednas, J.M. Dickson and S. Sourirajan, J. Appl. Polym. Sci. 18, 2829-2846 (1974).

39. T. Matsuura, M.E. Bednas, J.M. Dickson and S. Sourirajan, J. Appl. Polym. Sci. 19, 2473-2484 (1975)

40. H.L. Friedman and C.V. Krishnan, in Water - A Comprehensive Treatise, Chap. 1, F. Franks, Ed., Plenum, New York (1973).

41. J.A.V. Butler, Trans. Faraday Soc. 33, 229-236 (1937)

42. P.A. Smal 1, J. Appl. Chem. 3, 71-80 (1953).

43. L. Dresner, Desalination 15, 39-57 (1974).

44. T. Matsuura, P. Blais and S. Sourirajan, J. Appl. Polym. Sci. 20, 1515-1531 (1976).

45. J.M. Dickson, T. Matsuura, P. Blais and S. Sourirajan, J. Appl. Polym. Sci. 19, 801-819 (1975).

46. 0. Kutowy, T. Matsuura and S. Sourirajan, Parameters for Predicting Reverse Osmosis Performance of Cellulose Acetate Propionate Membranes, J. Appl. Polym. Sci. (in press) (1977).

47. T. Matsuura and S. Sourirajan, Characterization of Membrane Material, Specification of Membranes, and Predictability of Membrane Performance in Reverse Osmosis, Ind. Eng. Chem. Process Des. Dev. (submitted) (1977).

48. R. Bloch, M.A. Frommer, 0. Kedem, I. Feiner, A. Kedem and D. Lancet, RED Progress Report No. 499, OSW, U.S. Dept. Interior, Washington, D.C. (1969).

49. G.J. Gittens, P.A. Hitchcock, D.C. Sammon and G.E. Wakley, Desalination 8, 369-391 (1970).

50. E. Zisner and S. Loeb, Proc. Third Intern, Symp. on Fresh Water from the Sea, Dubrovnik, 2, 615-628(1970).

51. R.E. Kesting, synthetic Polymeric Membranes, Chap. 5, McGraw Hill, New York (1971).

52. R.E. Kesting, in Reverse Osmosis and Synthetic Membranes, Chap. 5, S. Sourirajan, Ed., National Research Council Canada, Ottawa (1977).

53. A.S. Michaels, Proc. Conf. on Reverse Osmosis and Uitrafiltration, Chemical Center, Lund University, Alnarp, Sweden, May 17, 1971.

54. H. Strathmann, P. Scheible and R.W. Baker, J. Appl. Polym. Sci. 15, 811-828 (1971).

55. M.A. Frommer and R. Matz, RED Progress Report No. 774, OSW, U.S. Dept. Interior, Washington, D.C. $(1972)$.

56. J.W. Carter, G. Psaras and M.T. Price, Desalination 12, 177-188 (1973).

57. M. Panar, H.H. Hoehn and R.R. Hebert, Macromolecules $\frac{6}{6}, 777-780$ (1973).

58. B. Kunst and S. Sourirajan, J. Appl. Polym. Sci. 14, 723-733 (1970).

59. B. Kunst and S. Sourirajan, J.Appl. Polym. Sci. 14, 1983-1996 (1970).

60. B. Kunst and S. Sourirajan, Desalination $8,139-1 \overline{52}(1970)$.

61. B. Kunst and S. Sourirajan, J.Appl. Polym. Sci. 14, 2559-2568 (1970).

62. H. Ohya and S. Sourirajan, J.Appl. Polym. Sci. $15,705-713$ (1971).

63. R. Pilon, B. Kunst and S. Sourirajan, J. Appl. Polym. Sci. 15, $1317-1336$ (1971).

64. L. Pageau and S. Sourirajan, J. Appl Polym. Sci. 16, 3185-3206 (1972).

65. H.K. Johnston and S. Sourirajan, J. Appl. Polym. Sci. 16, 3375-3380 (1972).

66. H.K. Johnston and S. Sourirajan, J.Appl. Polym. Sci. $\frac{17}{17}, 2485-2499$ (1973).

67. H.K. Johnston and S. Sourirajan, J.Appl. Polym. Sci. $17,3717-3726$ (1973).

68. W.L. Thayer, L. Pageau and S. Sourirajan, J. Appl. Polym. Sci. 18, 1891-1899 (1974).

69. H.K. Johnston and S. Sourirajan, J. Appl. Polym. Sci. 18, 2327-2338 (1974).

70. B. Kunst and S. Sourirajan, J. Appl. Polym. Sci. 18, 3423-3434 (1974).

71. 0. Kutowy and S. Sourirajan, J. Appl. Polym. Sci. 19, 1449-1460 (1975).

72. S. Sourirajan, in Encyclopedia of Environmental Science and Engineering, Vol. 2, 738-773, J.R. Pfafflin and E.N. Ziegler, Eds., Gordon and Breach, London (1976).

73. S. Sourirajan and B. Kunst, in Reverse Osmosis and Synthetic Membranes, Chap. 7, S. Sourirajan, Ed., National Research Council Canada, Ottawa (1977). 
74. W.L. Thayer, L. Pageau and S. Sourirajan, Process for Rapid Casting of Tubular Cellulose Acetate Membranes, Desal ination (in press) (1977).

75. T.A. Tweddle and S. Sourirajan, Effect of Ethanol-Water Mixture Gelation Medium During Formation of Cellulose Acetate Reverse Osmosis Membranes, J. Appl. Polym. Sci. (in press) (1977).

76. S. Kimura and S. Sourirajan, A.l.Ch.E.J. 13, 497-503 (1967).

77. S. Kimura and S. Sourirajan, Ind. Eng. Chem. Process Des. Dev. 7, 539-547 (1968).

78. S. Sourirajan and S. Kimura, Ind. Eng. Chem. Process Des. Dev. 6 , 504-516 (1967).

79. S. Kimura and S. Sourirajan, Ind. Eng. Chem. Process Des. Dev. $7,197-206$ (1968).

80. S. Kimura and S. Sourirajan, Ind. Eng. Chem. Process Des. Dev. I , 548-554 (1968).

81. H. Ohya and S. Sourirajan, Ind. Eng. Chem. Process Des. Dev. 8 , 131-142 (1969).

82. J.P. Agrawal and S. Sourirajan, Ind. Eng. Chem. Process Des. Dev. $8,439-449$ (1969). 83. J.M. Dickson, T. Matsuura, P. Blais and S. Sourirajan, J. Appl. Polym. Sci. 20,
1491-1499 (1976).

84. S. Sourirajan and T. Matsuura, in Reverse Osmosis and Synthetic Membranes, Chap. 3, S. Sourirajan, Ed., National Research Council Canada, Ottawa (1977).

85. H. Ohya and S. Sourirajan, A.1.Ch.E.J., 15, 829-836 (1969).

86. H. Ohya and S. Sourirajan, Reverse 0smosis System Specification and Performance Data for Water Treatment Applications, The Thayer School of Engineering, Dartmouth College, Hanover, N.H. (1971).

87. S. Sourirajan and H. Ohya, in Reverse Osmosis and Synthetic Membranes, Chap. 4, S. Sourirajan, Ed., National Research Council Canada, Ottawa (1977).

88. S. Kimura, S. Sourirajan and H. Ohya, Ind. Eng. Chem. Process Des. Dev. $18,79-89$ (1969).

89. H. Ohya and S. Sourirajan, Desalination 6, 153-178 (1969).

90. H. Ohya, S. Kasahara and S. Sourirajan, Desalination 16, 375-393 (1975). 91. T. Matsuura, A.G. Baxter and S. Sourirajan, Ind. Eng. Chem. Process Des. Dev. 16,
82-89 (1977).

92. S. Sourirajan and J.P. Agrawal, Ind. Eng. Chem. 61 (11), 62-89 (1969).

93. J.P. Agrawal and S. Sourirajan, Ind. Eng. Chem. Process Des. Dev. 9, i2-18 (1970).

94. T. Matsuura and S. Sourirajan, Ind. Eng. Chem. Process Des. Dev. 10, 102-108 (1971).

95. R. Rangarajan, T. Matsuura, E.C. Goodhue and S. Sourirajan, Predictability of Reverse Osmosis Performance of Porous Cellulose Acetate Membranes for Mixed Uni-univalent Electrolytes in Aqueous Solutions, Ind. Eng. Chem. Process Des. Dev. (submitted)

96. T. Matsuura, A.G. Baxter and S. Sourirajan, Acta Alimentaria 2 , 109-150 (1973).

97. T. Matsuura, A.G. Baxter and S. Sourirajan, J. Food Sci. 39, $704-711$ (1974).

98. T. Matsuura, A.G. Baxter and S. Sourirajan, J. Food Sci. 40, 1039-1046 (1975).

99. E.N. Pereira, T. Matsuura and S. Sourirajan, J. Food Sci. 41, 672-680 (1976).

100. T. Matsuura and S. Sourirajan, A Fundamental Approach to Application of Reverse Osmosis for Food Processing, Paper presented at the session on Applications of Membranes to Food Processing at the A.I.Ch.E. meeting at Chicago, 111., during Nov. 14-18, 1976.

101. S. Sourirajan, Nature 203, 1348-1349 (1964).

102. J. Kopecek and S. Sourirajan, Can. J. Chem. 47, 3467-3469 (1969).

103. J. Kopecek and S. Sourirajan, Ind. Eng. Chem. Process Des. Dev. 9 , 5-12 (1970).

105. J.P. Agrawal and S. Sourirajan, J. Appl. Polym. Sci. 13, 1065-1068 (1969).

106. J.P. Agrawal and S. Sourirajan, J.Appl. Polym. Sci. 14, 1303-1321 (1970).

107. S. Sourirajan and J.P. Agrawal, in Reverse Osmosis and Synthetic Membranes, Chap. 26, S. Sourirajan, Ed., National Research Council Canada, Ottawa (1977).

108. S. Sourirajan, in Reverse Osmosis and Synthetic Membranes, Chap. 28. S. Sourirajan, Ed., National Research Council Canada, Ot tawa (1977). 